\title{
Evolução metamórfica/metassomática paleoproterozóica do Complexo Saúde, da Bacia Jacobina e de leucogranitos peraluminosos na parte norte do Cráton do São Francisco
}

\author{
Carlson de Matos Maia Leite ${ }^{1,2}$, Johildo Salomão Figueiredo Barbosa ${ }^{1}$, \\ Christian Nicollet ${ }^{3} \&$ Pierre Sabatét
}

\begin{abstract}
Resumo O Complexo Saúde e a Bacia Jacobina, localizados na parte norte do Cráton do São Francisco, são constituídos por rochas metassedimentares, metamorfizadas durante a orogenia paleoproterozóica $(\approx 2,08-1,88$ $\mathrm{Ga}$ ) e associadas a leucogranitos. Os kinzigitos e paragnaisses não-granadíferos do Complexo Saúde, os xistos aluminosos da Bacia Jacobina e os leucogranitos são portadores de assembléias mineralógicas relacionadas à colisão orogênica. Nos kinzigitos, a granada, e nos paragnaisses, a estaurolita, associadas à sillimanita + quartzo + biotita foram formadas durante a trajetória metamórfica progressiva, enquanto cordierita e plagioclásio cristalizaram durante a trajetória retrógrada associada à descompressão orogênica. Nos xistos aluminosos, granada e estaurolita cristalizaram durante o metamorfismo progressivo, porém andaluzita e plagioclásio expressam o retrometamorfismo. Os paragnaisses não-granadíferos, os andaluzita-xistos e os leucogranitos contêm microestruturas constituídas por fibrolita + quartzo + muscovita. Essas microestruturas se formaram por circulação de fluidos redutores que lixiviaram principalmente cátions-base dos silicatos preexistentes, caracterizando metassomatismo ocorrido durante e/ ou após a descompressão orogênica. Os leucogranitos atuaram como motores termodinâmicos na mobilização dos fluidos crustais. Esse evento de metassomatismo foi responsável por inflexões quase isobáricas $(\approx 3,0 \mathrm{kbar})$ nas trajetórias $\mathrm{P}-\mathrm{T}$ regressivas dos paragnaisses não-granadíferos e dos xistos aluminosos, em direção a temperaturas próximas de $600^{\circ} \mathrm{C}$. Nos kinzigitos, a ausência de fibrolita e muscovita e as estimativas de geotermometria, entre as fácies granulito baixo e anfibolito alto, sugerem um posicionamento alóctone dessas rochas provenientes da infracrosta do orógeno.
\end{abstract}

Palavras-chave: Complexo Saúde, Bacia Jacobina, metamorfismo, metassomatismo, orogenia paleoproterozóica.

\begin{abstract}
PALEOPROTEROZOIC METAMORPHIC/ METASOMATIC EVOLUTION OF THE SAÚDE COMPLEX, JACOBINA BASIN AND OF THE PERALUMINOUS LEUCOGRANITES IN THE NORTHERN PART OF SÃO FRANCISCO CRATON. The Saúde Complex and the Jacobina Basin, located in the northern part of the São Francisco Craton, are constituted by metasedimentary rocks, metamorphosed during the paleoproterozoic orogeny $(\approx 2.08-1.88 \mathrm{Ga})$, and are associated to leucogranites. The kinzigites and the non-garnetiferous paragneisses of the Saúde Complex, the aluminous schists of the Jacobina Basin and the leucogranites contain mineral assemblages related to the orogenic collision. The garnet in the kinzigites and staurolite in the paragneisses, associated to sillimanite + quartz + biotite, constitute mineral assemblages formed during the progressive metamorphic path whereas cordierite and plagioclase crystallized during the retrometamorphism associated to the orogenic decompression. In the aluminous schists, garnet and staurolite crystallized during the metamorphic progressive path, but andaluzite and plagioclase record the retrometamorphism. The non-garnetiferous paragneisses, the andaluzite-schists and the leucogranites have fibrolite-quartz-muscovitebearing microstructures formed from the circulation of reducing fluids that lixiviated mainly base-cations of the preexisting silicates. Those microstructures characterize an event of metasomatism that occurred during and/or after the orogenic decompression with the leucogranites acting as thermodynamic triggers in the mobilization of the crustal fluids. The metasomatic event was responsible for almost isobaric inflections $(\approx 3.0 \mathrm{kbar})$ in the regressive $\mathrm{P}-\mathrm{T}$ path of the non-garnetiferous paragneisses and of the aluminous schists, toward temperatures near $600 \mathrm{oC}$. The absence of fibrolite and muscovite in the kinzigites besides geothermometry estimations, placed between the low-granulite and the high-amphibolite facies, suggest allochthonous positioning of those rocks originated from the orogen infracrust.
\end{abstract}

Keywords: Saúde Complex, Jacobina Basin, metamorphism, metasomatism, paleoproterozoic orogeny.

1 -Núcleo de Geologia Básica/Centro de Pesquisa em Geofísica e Geologia, Universidade Federal da Bahia, Salvador (BA), Brasil. Emails: cmml@ufba.br e johildo@cppg.ufba.br

2 - PETROBRAS/ UN-BA/ ATEX/ SE, Pituba, Salvador (BA), Brasil. E-mail: cmml@petrobras.com.br

3 - Laboratoire Magmas et Volcans-UMR, Université Blaise Pascal, Clermont-Ferrand, France. E-mail: c.nicollet@opgc.univ-bpclermont.fr

4 - IRD - Institut de Recherche pour le Développement, Brasília (DF), Brasil. E-Mail - ird@apis.com.br 
INTRODUÇÃo O Complexo Saúde (Couto et al. 1978) e a Bacia Jacobina (Leo et al. 1964) são unidades constituídas por rochas metassedimentares situadas na parte norte do Cráton do São Francisco (Almeida 1967) (Fig. 1). Associados a essas rochas ocorrem leucogranitos, originados durante a orogenia riaciana/ orosiniana $(\approx$ 2,08-1,88 Ga) (Torquato et al. 1978, Sabaté et al. 1990).

Embora essas unidades tenham sido objetos de trabalhos de mapeamento e de exploração mineral ao longo das últimas décadas, pouco se conhece sobre os processos e mecanismos responsáveis por suas evoluções metamórficas durante essa orogenia.

Este trabalho apresenta os principais resultados dos estudos de mineralogia e petrologia dos metapelitos dessas unidades e dos leucogranitos associados, que ocorrem nos municípios de Mundo Novo e de Ja- cobina no estado da Bahia (Fig. 2). Foram identificadas as reações mineralógicas e as condições de pressão e temperatura em que se formaram as assembléias mineralógicas dos metapelitos, bem como, as suas trajetórias pressão-temperatura $(P-T)$. Assembléias mineralógicas portadoras de fibrolita e muscovita, presentes nos leucogranitos e em parte dos metapelitos, sugerem que essas rochas passaram por um evento de evolução metassomática (e.g. Vernon 1979, Kerrick 1988) que se sucedeu durante e/ ou após a descompressão orogênica. Os processos e as reações metassomáticas são também discutidos e interpretados, bem como, o papel dos leucogranitos como fonte adicional de calor, além de agente catalisador de mobilização dos fluidos crustais. Destaca-se também que as modificações nas trajetórias retrógradas do metamorfismo estão relacionadas a esse

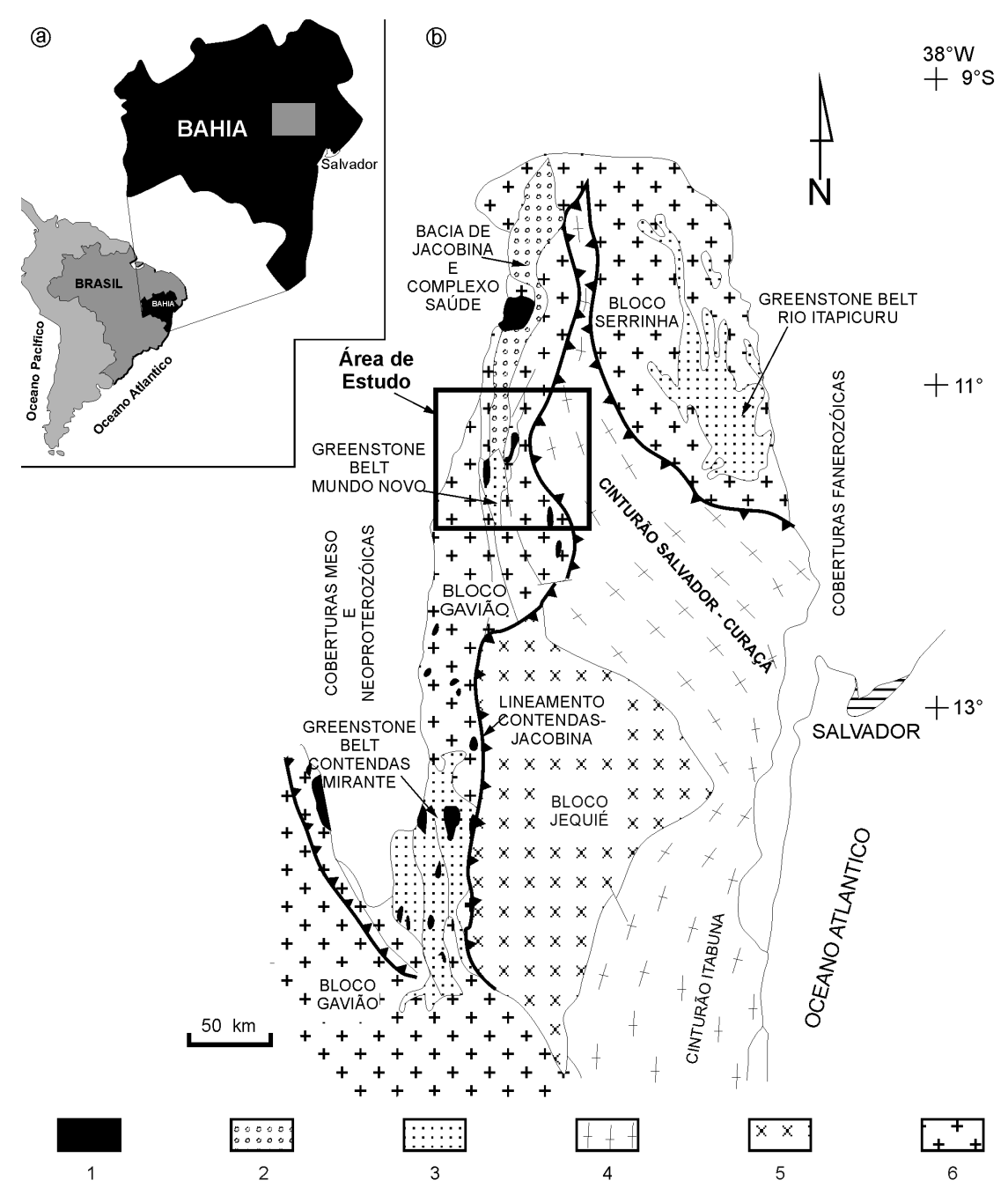

Figura 1 - Localização da área de estudo. (a) Mapa do Brasil com localização do estado da Bahia. O retângulo marca a área de estudo. (b) Mapa geológico esquemático da região que contém a área de estudo e os domínios tectônicos no estado da Bahia (modificado de Sabaté et al. 1990). 1 Leucogranitos; 2 - Coberturas metassedimentares; 3 - Greenstone Belts; 4 - Cinturão Itabuna-Salvador-Curaçá (granulítico); 5 - Bloco cratônico Jequié (granulítico); 6 - Blocos cratônicos Gavião e Serrinha (gnáissicomigmatíticos). 


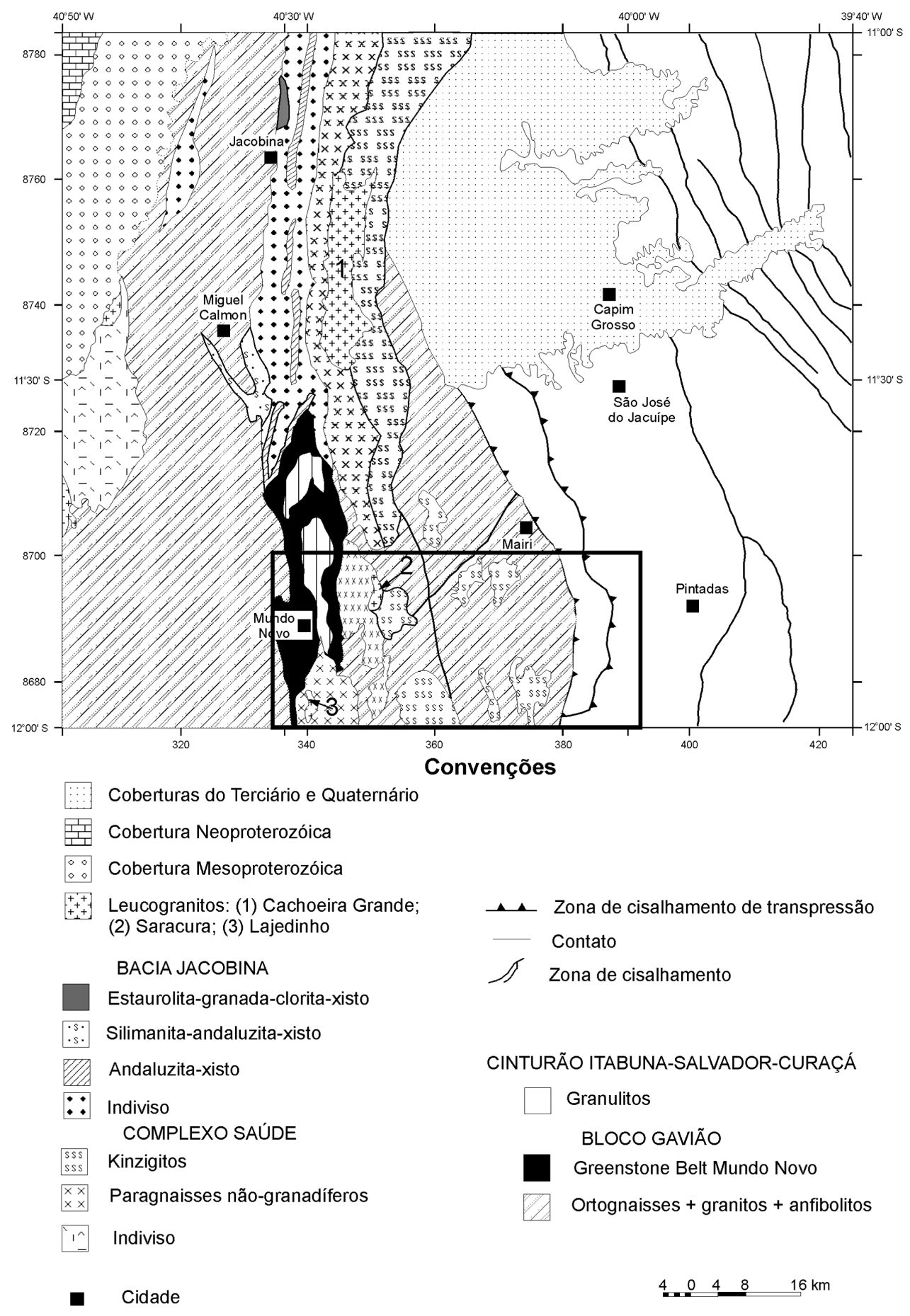

Figura 2 - Mapa geológico esquemático da área de estudo (modificado de Melo et al. 1995; Mascarenhas et al. 1998). O retângulo marca a área da figura 4.

evento de metassomatismo.

GEOLOGIA REGIONAL As unidades geotectônicas que constituem a infra-estrutura do Cráton do São Francisco na área de estudo (Figs. 1 e 2) são: (i) Bloco Gavião e suas coberturas representadas pela Bacia Jacobina e o Complexo Saúde e (ii) Cinturão ItabunaSalvador-Curaçá (Barbosa \& Sabaté 2002, 2004).

O Bloco Gavião (Marinho \& Sabaté 1982) é constituído por domos ortognáissicos-migmatíticos tipo TTG com idades entre 3,4 e 3,04 Ga (Mougeot
1996, Peucat et al. 2002), metamorfizados na fácies anfibolito (Melo et al. 1995), pelo Greenstone Belt de Mundo Novo (Mascarenhas \& Silva 1994) com idade de 3,3 Ga (Peucat et al. 2002), metamorfizado na fácies anfibolito/ xisto verde (Leite 2002), além de granitóides diversos.

A Bacia Jacobina (Leo et al. 1964) e o Complexo Saúde (Couto et al. 1978) são compostos por rochas metassedimentares. As rochas da Bacia Jacobina estão metamorfizadas na fácies anfibolito/ xisto verde e as do Complexo Saúde na fácies anfibolito/ granulito (Melo 
et al 1995; Leite 2002). Dados geocronológicos dos zircões detríticos da Bacia Jacobina definem populações de 3,4-3,3 Ga e de 2,08 Ga (Mougeot 1996), interpretadas como idades das rochas-fonte, provenientes do Bloco Gavião e do Cinturão Itabuna-Salvador-Curaçá. Idades de 2,08 e 2,05 Ga do Complexo Saúde se referem a sua evolução metamórfica (Leite, 2002).

Os leucogranitos ocorrem no Bloco Gavião e no Cinturão Salvador-Curaçá e são de filiação peraluminosa (Cuney et al. 1990). Apresentam estruturas de fluxo magmático e/ ou milonítica, controladas pela direção das tensões e pela intensidade da deformação regional (Leite et al. 2001). No Bloco Gavião, suas idades de cristalização variam entre 2,15 e 1,88 Ga (Torquato et al. 1978, Sabaté et al. 1990).

O Cinturão Itabuna-Salvador-Curaçá está metamorfizado na fácies granulito (Barbosa \& Sabaté 2002). Na sua parte norte (Cinturão Salvador-Curaçá) é constituído por tonalitos-trondhjemitos-granodioritos (Melo et al. 1995) e na parte sul (Cinturão Itabuna) ele é formado por tonalitos-trondhjemitos (Barbosa \& Sabaté 2002). Em ambas as partes ocorrem rochas supracrustais. Idades de 2,7 Ga são relacionadas aos protólitos gerados em ambiente de arco magmático (Silva et al. 1997) e as de 2,08 Ga ao metamorfismo granulítico (Silva et al. 1997, Leite 2002) e a tonalitos granulitizados, gerados em arco magmático paleoproterozóico (Pinho 2005).

A configuração geométrica dessas unidades geotectônicas na parte norte-oriental do estado da Bahia (Fig. 1b) é resultante da colisão oblíqua entre si durante o Riaciano-Orosiniano (Barbosa \& Sabaté 2002, 2004). Sabaté (1996) caracterizou dois eventos de deformação para essa colisão. O primeiro é atribuído a uma tectônica tangencial que formou dobras com planos axiais suborizontais e falhas de empurrão. $\mathrm{O}$ segundo evento é caracterizado por falhas transcorrentes, dobras com eixos suborizontais $\mathrm{N}-\mathrm{S}$ e foliação de plano axial subverticalizada. Essas estruturas em conjunto com as lineações de estiramento mineral indicam vergência para oeste e movimentação sinistral.

\section{GEOLOGIA LOCAL DOS METAPELITOS E DOS LEUCOGRANITOS}

Complexo Saúde (CS) O Complexo Saúde CS constitui faixa contínua, situada à leste da Bacia Jacobina e do Greenstone Belt de Mundo Novo, além de afloramentos isolados sobrepostos aos ortognaisses do Bloco Gavião (Fig. 2). Os metapelitos são constituídos por kinzigitos e paragnaisses não-granadíferos, os últimos sempre situados à oeste dos primeiros (Fig. 2). Os kinzigitos apresentam estrutura migmatítica (Fig. 3a,b) com melanossomas/ mesossomas enriquecidos em cordierita e biotita e leucossomas em quartzo e feldspato. Granada e cordierita constituem porfiroblastos, sendo que granada ocorre com auréolas de plagioclásio nos leucossomas e de cordierita nos melanossomas. Nos paragnaisses não-granadíferos, as principais texturas são formadas por porfiroblastos de cordierita e por nódulos elipsoidais compostos por quartzo + sillimanita + muscovita (Fig. 3c).

Na região de Italegre-Mundo Novo, as zonas de cisalhamento dúcteis e dúcteis-rúpteis de Mairi e Bonsucesso (Fig. 4) caracterizam a frente colisional transpressional e de movimentação geral sinistral (Loureiro 1991, Melo et al. 1995) entre o Bloco Gavião e o Cinturão Salvador-Curaçá. Próximos a esta frente, os afloramentos de kinzigitos são contornados por ortognaisses do Bloco Gavião (Fig. 4) e neles ocorrem raras e pequenas dobras recumbentes, parasíticas e assimétricas $\left(\mathrm{F}_{1}\right)$, nas quais o bandamento composicional $\left(\mathrm{S}_{1}\right)$ mergulha suave para NE e a assimetria dos flancos indica vergência para WNW (Fig. 3b). Estas dobras são transpostas por uma foliação milonítica $\left(\mathrm{S}_{2}\right)$, de alto ângulo e direção meridiana, que contém uma lineação de estiramento mineral de baixo a médio rake, ora para norte ora para sul. Estas feições de deformação, no seu conjunto, sugerem uma tectônica tangencial (D1) de movimentação para WNW procedida por tectônica transpressional (D2) de movimentação NNW-SSE (Fig. 4). A foliação milonítica de alto ângulo é predominante nos paragnaisses não-granadíferos que mostram, ainda, bandamento composicional $\left(\mathrm{S}_{0} / / \mathrm{S}_{1}\right)$ verticalizado e dobrado por arrastos sinistrais (Fig.3c) ou dextrais.

Bacia Jacobina (BJ) A Bacia Jacobina BJ se estende ao longo de uma faixa de direção meridiana (Fig. 2), cujos limites adotados correspondem, com algumas modificações, àqueles de Leo et al. (1964). Na sua porção basal, ocorrem xistos portadores de porfiroblastos de estaurolita e granada em matriz rica em clorita e magnetita. Próximo à cidade de Miguel Calmon, os xistos contêm porfiroblastos de andaluzita e agregados aciculares de sillimanita. Na parte central da bacia, ocorre uma associação de filonitos, filitos, metacherts, formações ferríferas bandadas e xistos com porfiroblastos de andaluzita. Todas essas rochas apresentam foliação com direção meridiana e forte mergulho para leste que acompanham as zonas de cisalhamento regionais.

Leucogranitos (LG) Os leucogranitos demarcam três maciços no lado oriental da BJ, denominados de Cachoeira Grande, Saracura e Lajedo (Figs. 2,4). Estes maciços apresentam foliação subverticalizada com direção NNE e fácies heterogêneas, granadíferas e nãogranadíferas. Notam-se filões pegmatóides enriquecidos em muscovita e orientados na direção NW. Destaca-se no bordo ocidental do maciço Saracura (Fig. 2), a presença de nódulos de fibrolita + quartzo ao longo de superfícies de cisalhamento com direção NNE (Fig. $3 d)$.

\section{PETROGRAFIA DOS METAPELITOS E DOS LEUCOGRANITOS}

Complexo Saúde (CS) Com relação a morfologia das foliações dos kinzigitos e paragnaisses não-granadíferos, segundo as proposições de Passchier \& Trouw (1996), elas variam de contínua/ espaçada a milonítica e são subdivididas em domínios de xistosidade, ricos em cordierita e biotita, e em domínios lenticulares, 

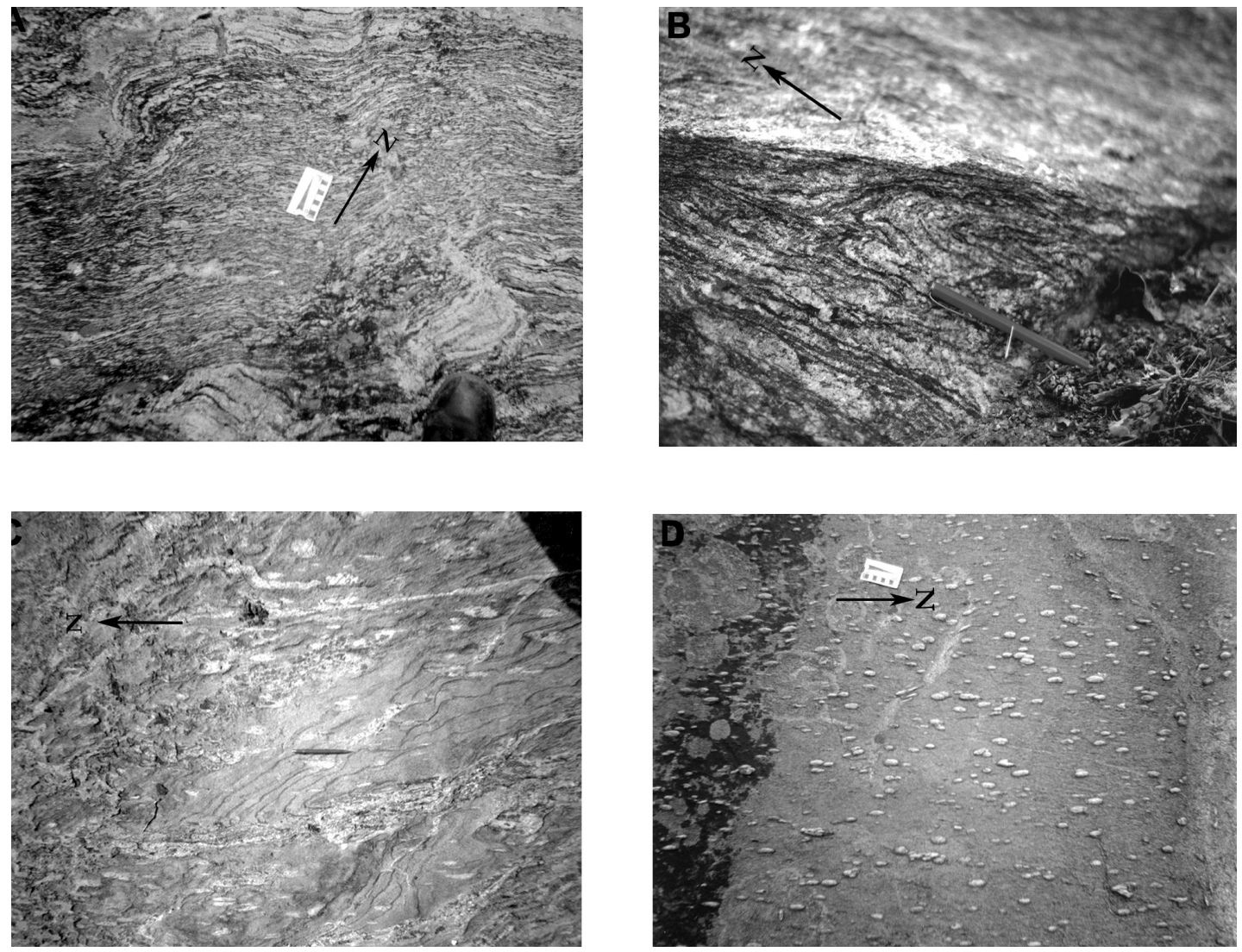

Figura 3 - Estruturas dos metapelitos e dos leucogranitos estudados. (a) Estrutura migmatizada dos kinzigitos do CS (afloramento CL138); (b) Kinzigito do CS com bandamento composicional $\left(S_{1}\right)$ formando dobra isoclinal $\left(F_{\gamma}\right)$ com plano axial suborizontal e vergência que indicam transporte tangencial para NW (afloramento CL122); (c) Paragnaisse não-granadifero do CS apresentando bandamento composicional $\left(S_{\gamma} / / S_{\nu}\right)$ dobrado por arrasto sinistral e nódulos de sillimanita + quartzo \pm muscovita (afloramento CL027); (d) Feições no bordo ocidental do leucogranito Saracura mostrando nódulos de quartzo + sillimanita ao longo de superfícies de cisalhamento, além de filões com granada ao longo de zonas dilatacionais (afloramento CL012).

quartzo-feldspáticos. Nos kinzigitos, a granada forma porfiroblastos e poiquiloblastos com foliação interna constituída por quartzo, plagioclásio e biotita. Os grãos menores de granada estão inclusos em plagioclásio (Fig. 5a) ou cordierita ou são orlados por biotita e cordierita (Fig. 5b). A sillimanita ocorre como inclusões em plagioclásio (Fig. 5a) ou cordierita. A biotita, com pleocroísmo variando de marrom a marrom-avermelhado, forma porfiroblastos nos domínios de xistosidade e grãos intersticiais nos domínios lenticulares. Os opacos estão associados à biotita e granada ou inclusos em plagioclásio ou cordierita. A cordierita e o plagioclásio constituem grãos finos ao redor da granada ou poiquiloblastos e porfiroblastos. O quartzo ocorre em grãos com extinção ondulante, por vezes constituindo ribbons.

Nos paragnaisses não-granadíferos, a cordierita e o plagioclásio formam poiquiloblastos, notando-se que a primeira exibe raras inclusões de estaurolita (Fig. 5c) ou sillimanita. A biotita apresenta pleocroísmo marrom avermelhado. Esta assembléia está parcialmente substituída por fibrolita (Figs. 5d,e), especialmente a cordierita que está pinitizada (Fig. 5d), notando-se que a biotita ao ser substituída, assume um pleocroísmo marrom amarelado. A muscovita é de cristalização tardia, substituindo a biotita e a fibrolita. Nos nódulos a muscovita constitui simplectitos com quartzo (Fig. 5e) ou forma porfiroblastos (Fig. 5f). A microclina não é comum e está em contato com os minerais substituídos por fibrolita (Fig. 5e). O quartzo forma desde grãos intersticiais até porfiroblastos com forte extinção ondulante. Inclusões de monazita e zircão são comuns nos paragnaisses e nos kinzigitos, geralmente em biotita e cordierita, sendo que nos kinzigitos ocorrem, também, em plagioclásio e granada.

Bacia Jacobina (BJ) Metapelitos na Bacia Jacobina incluem estaurolita-granada-clorita-xisto, sillimanitaandaluzita-xisto e andaluzita-xisto. No estaurolitagranada-clorita-xisto, poiquiloblastos/ porfiroblastos de granada e estaurolita e domínios lenticulares, ricos em estaurolita e coríndon, ocorrem em matriz xistosa constituída por clorita e magnetita (Fig. 6a). A granada contém, por vezes, uma fina foliação interna composta por quartzo, cloritóide e muscovita (Fig. 6b). Os porfi- 


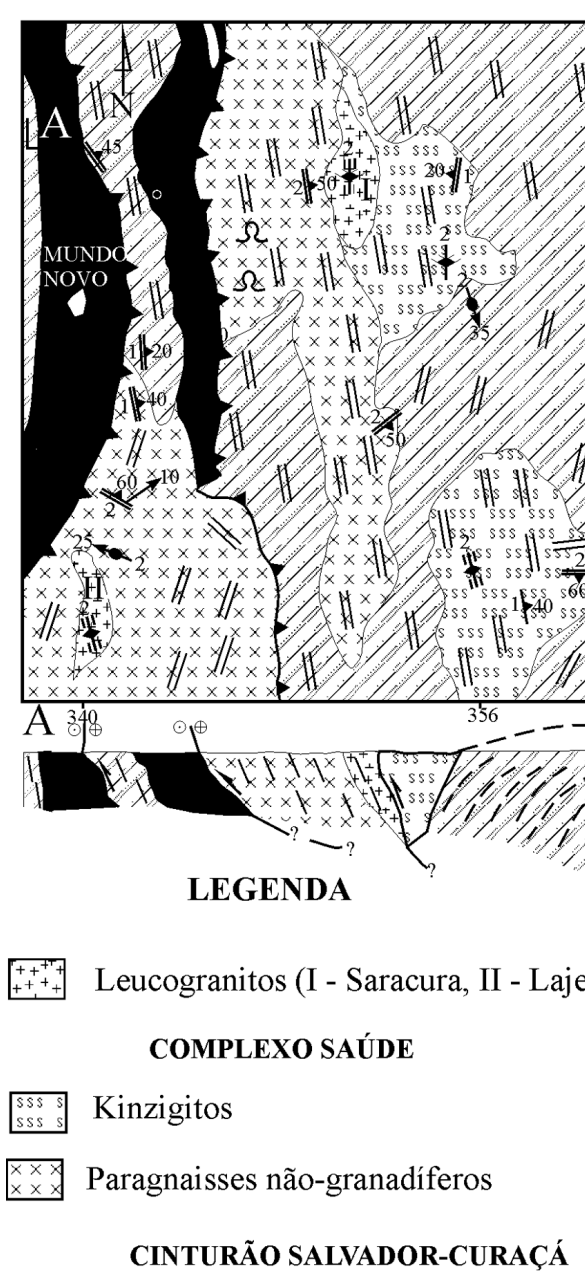

Granulitos

\section{BLOCO GAVIÃo}

$\square$

Greenstone Belt de Mundo Novo

Ortognaisses

in Cidade

- Povoado

\section{Contato}

Falha ou fratura

Lona de cisalhamento oblíqua sinistral (mapa)

$\Omega$ Dobramento em bainha

$\oplus$ Zona de cisalhamento oblíqua sinistral (perfil)

$\stackrel{\oplus}{\odot}$ Zona de cisalhamento sinistral

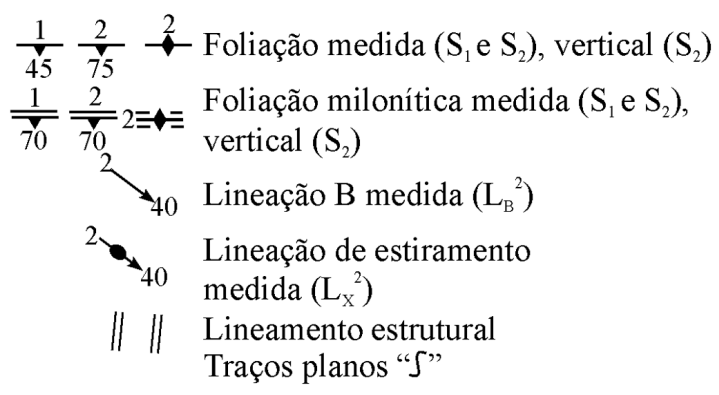

Figura 4 - Mapa e perfil geológico esquemáticos da região de Italegre-Mundo Novo (modificado de Melo et al. 1995; Mascarenhas et al. 1998).

roblastos de estaurolita ocorrem em sítios onde a granada não está presente. A clorita exibe microestruturas de exsolução de opacos, enquanto a dolomita ocorre nos bordos dos porfiroblastos de granada (Fig. 6a).

Nas rochas com andaluzita, este mineral e o plagioclásio formam poiquiloblastos em matriz xistosa constituída por domínios ricos em quartzo ou mica. Os poiquiloblastos de andaluzita contêm inclusões de plagioclásio (Fig. 6c), biotita e sillimanita prismática (Fig. 6d), raramente de estaurolita (Fig. 6e) e uma foliação interna composta por quartzo, muscovita e clorita. Os poiquiloblastos de plagioclásio contêm a mesma foliação interna que ocorre na andaluzita (Fig. 6c). A biotita apresenta pleocroísmo marrom avermelhado ou verde amarelado e forma porfiroblastos ou grãos menores nos domínios xistosos. A cor verde ocorre quando biotita está parcialmente substituída por clorita ou fibrolita. Este último mineral forma agregados aciculares ao redor ou ao longo de micro-fraturas nos poiquiloblastos de andaluzita (Fig. 6d). O quartzo apresenta forte extinção ondulante e constitui grãos que, por vezes, formam sigmóides assimétricos e ribbons. Muscovita e opacos são predominantes nos domínios xistosos. A muscovita aparece em grãos de crescimento epitaxial sobre a biotita ou incluindo fibrolita. Vale destacar que as rochas com andaluzita mostram como acessórios, geralmente como inclusões, zircão, monazita, rutilo e grafita. 

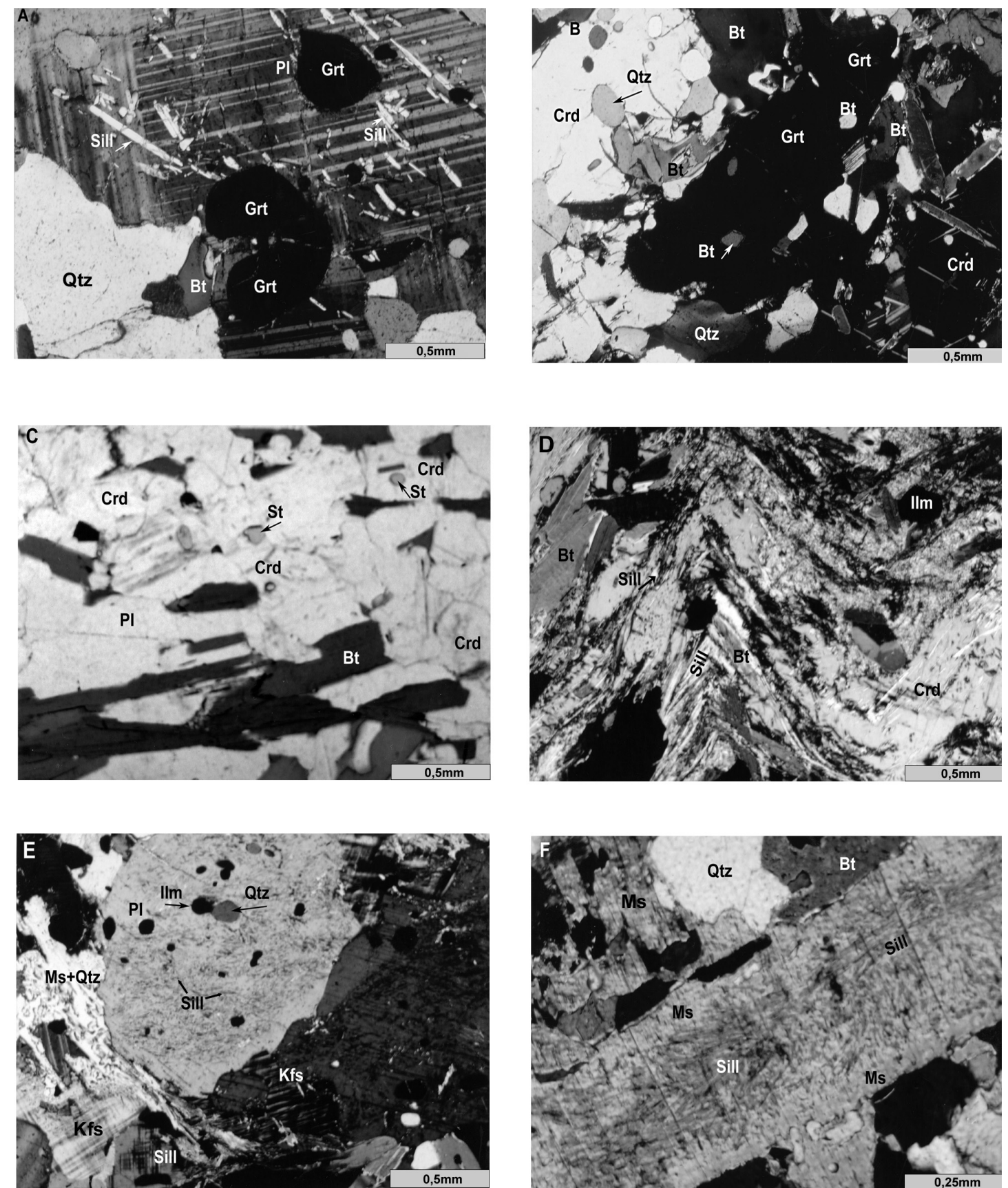

Figura 5 - Microestruturas nos metapelitos do Complexo Saúde. (a) Inclusões de granada (Grt) e sillimanita (Sill) em plagioclásio (Pl), em kinzigito próximo de Mundo Novo (amostra CL138); (b) Porfiroblasto alongado de granada (Grt), orlado por cordierita $(\mathrm{Crd})+$ biotita (Bt) + quartzo (Qtz), em kinzigito próximo do Cinturão Salvador-Curaçá (amostra CL23); (c) Estaurolita (St) inclusa em cordierita (Crd), em paragnaisse não-granadifero (amostra CL074); (d) Cordierita (Crd) pinitizada e substituida por fibrolita (Sill) que por sua vez substitui também a biotita (Bt), em paragnaisse não-granadifero próximo do leucogranito Saracura (amostra CL25); (e) Plagioclásio (Pl) substituido por fibrolita (Sill) com inclusões de ilmenita (Ilm) e quartzo (Qtz), ao lado de simplectito de muscovita (Ms) + quartzo (Qtz), em paragnaisse não-granadífero próximo de Mundo Novo (amostra CLO12E); (f) Muscovita (Ms) englobando feixe de fibrolita (Sill), microdobrada, em paragnaisse não-granadífero próximo de Mundo Novo (amostra CL010). As abreviaturas dos minerais são aquelas de Kretz (1983).

Leucogranitos (LG) Suas texturas variam de granular hipidiomórfica/ xenomórfica à foliação contínua ou milonítica. Fenocristais e porfiroclastos de plagioclásio e de pertita contêm raras inclusões de mesopertita, quartzo e opacos. Plagioclásio e pertita são dominantes na matriz e seus grãos mostram extinção diferenciada nos bordos, sugerindo zoneamento composicional. A biotita mostra-se em quatro tipos distintos: (i) biotita 

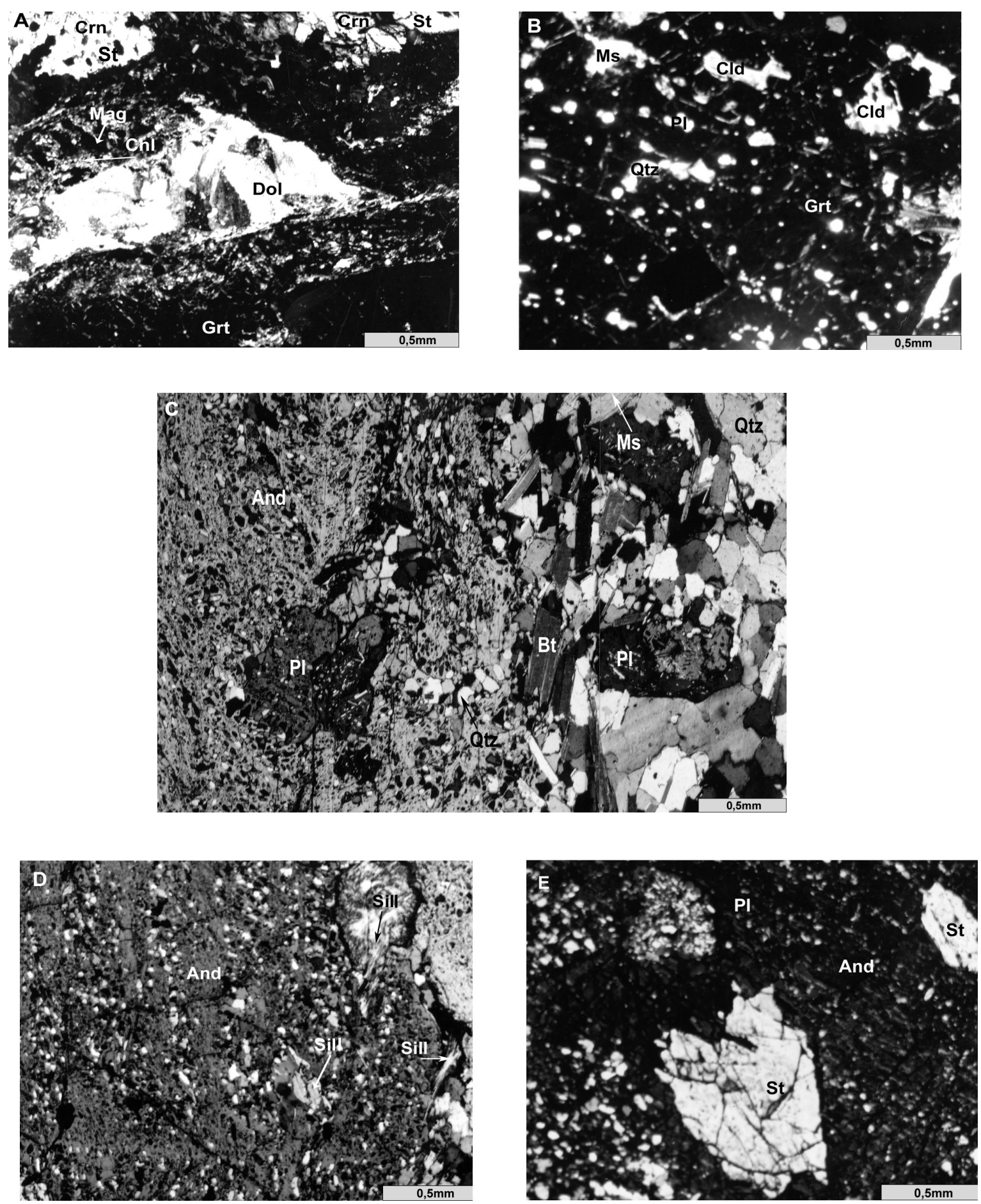

Figura 6 - Microestruturas nos metapelitos da Bacia Jacobina. (a) Porfiroblasto de granada (Grt) com dolomita (Dol) nos bordos, além de agregados de estaurolita (St) + coríndon (Crn), em matriz de clorita (Chl) + magnetita (Mag) (amostra 20534); (b) Inclusões de cloritóide (Cld) + quartzo (Qtz) + muscovita (Ms) em granada (amostra 20534); (c) Poiquiloblasto de andaluzita (And) com inclusão de plagioclásio (Pl) e foliação interna constituída por Ms + Qtz + Bt (amostra CL 073); (d) Inclusões de sillimanita (Sill) prismática e biotita (Bt) em andaluzita (And), além da fibrolita (Sill) que se projeta internamente no poiquiloblasto, ao longo de microfratura (amostra 073); (e) Inclusões de estaurolita (St) e plagioclásio (Pl) em poiquiloblasto de andaluzita (And) (amostra 082).

esverdeada, parcialmente transformada a clorita quando em contato com granada (Fig. 7a); (ii) biotita marrom avermelhada $\left(\mathrm{Bt}_{1}\right)$, inclusa em plagioclásio ou pertita ou, ainda, no núcleo dos nódulos (Fig. 7b); (iii) biotita marrom amarelada, parcialmente substituída por fibrolita e; (iv) biotita marrom $\left(\mathrm{Bt}_{2}\right)$ ao redor dos nódulos de quartzo + fibrolita (Fig. 7b). A microclina ocorre de modo intersticial ou engloba o plagioclásio, enquanto 

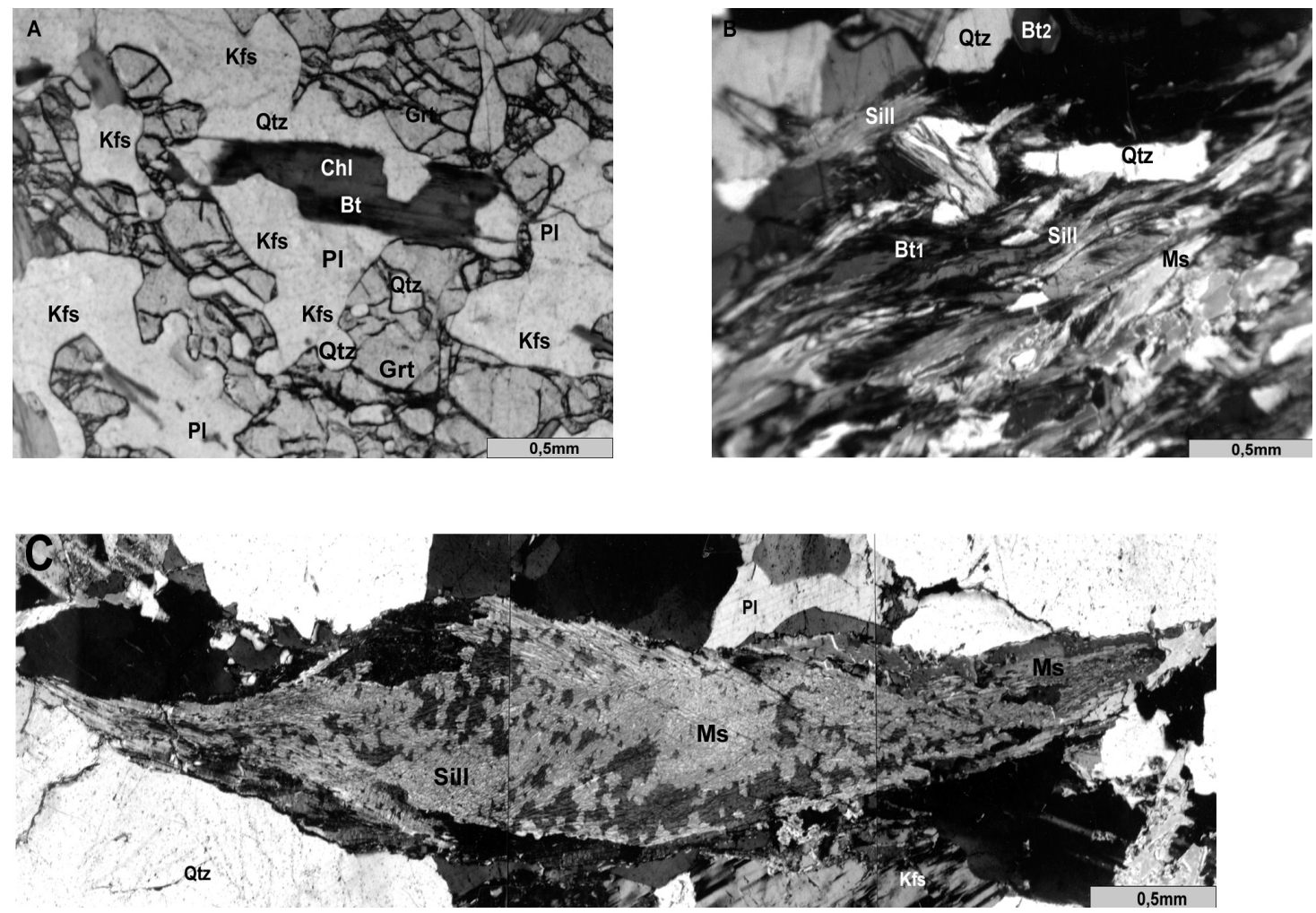

Figura 7 - Microestruturas nos leucogranitos. (a) Granada (Grt) englobando quartzo (Qtz) e microclina ( $\mathrm{Kfs}$ ) ao lado de biotita (Bt), parcialmente transformada a clorita (Chl) no leucogranito Saracura (amostra CL29E1); (b) Feição microscópica de nódulo de quartzo (Qtz) + fibrolita (Sill) onde, no núcleo ocorrem restos de biotita (Bt,) parcialmente substituída por fibrolita e muscovita (Ms), enquanto no bordo ocorre grão límpido de biotita (Bt $t_{2}$, no leucogranito Saracura (amostra CL29E4); (c) Mica-fish de muscovita (Ms) incluindo feixes de fibrolita (Sill), no leucogranito Cachoeira Grande (amostra CL53).

a granada forma grãos poiquilíticos com inclusões de quartzo e microclina (Fig. 7a). Fibrolita e muscovita substituem biotita, sendo que muscovita substitui também a fibrolita (Fig. $7 \mathrm{~b}, \mathrm{c}$ ). O quartzo constitui grãos com forte extinção ondulante que interlobam ou incluem os de feldspato.

QUÍMICA MINERAL Análises de química mineral foram obtidas no Laboratório de Microssonda Eletrônica da Université Blaise Pascal, Clermont Ferrand, França. A microssonda CAMECA SX 100 foi operada em condições de $15 \mathrm{kV}, 15 \mathrm{nA}$ com espessura do raio incidente entre 5 e $10 \mu \mathrm{m}$. O tempo de análise para cada elemento foi de 10s. Padrões naturais calibraram todos os elementos com exceção do $\mathrm{Zn}$, calibrado com esfalerita sintética. Utilizou-se dos programas NORM (Ulmer 1993) e PASFORM (Bjerg et al. 1995) para cálculo das fórmulas estruturais dos minerais. $\mathrm{Fe}^{+3}$ foi calculado através das seguintes relações: ${ }^{\mathrm{V} I} \mathrm{Fe}^{+3}={ }^{\mathrm{IV}} \mathrm{Al}^{+3}$ $\left({ }^{\mathrm{VI}} \mathrm{Al}^{+3}+\mathrm{Cr}_{\text {total }}\right) \mathrm{e}^{\mathrm{Vl}} \mathrm{Fe}^{+2}=\mathrm{Fe}_{\text {total }}-{ }^{\mathrm{Vl}} \mathrm{Fe}^{+3}$ com exceção da granada, onde se considerou $\mathrm{Fe}^{+3}=4-\left(\mathrm{Al}^{\mathrm{VI}}+\mathrm{Ti}+\mathrm{Cr}\right)$.

Granada Nas rochas metassedimentares, a granada é uma solução sólida rica em almandina (Tab. 1). Nos kinzigitos do CS, ela está enriquecida nos componentes espessartita e andradita e sua composição é de $\mathrm{Alm}_{66-78-}$
$\operatorname{Prp}_{10-17} \mathrm{Sps}_{07-20} \mathrm{And}_{02-03}$. No xisto da BJ a composição é $\mathrm{Alm}_{76-85} \operatorname{Prp}_{15-24} \mathrm{Sps}_{00} \mathrm{And}_{00-01}$. Perfis composicionais nos porfiroblastos dos kinzigitos mostram centros enriquecidos em Mg e Ca e bordos em Fe e Mn (Leite 2002). Nos leucogranitos, a composição da granada é $\mathrm{Alm}_{76-79-}$ $\operatorname{Prp}_{05-07} \mathrm{Sps}_{13-17} \mathrm{And}_{02}$ e está enriquecida em espessartita e empobrecida em piropo em relação àquela das rochas metassedimentares (Tab. 1).

Biotita Nas rochas metassedimentares, a biotita está projetada entre os pólos da anita e da flogopita (Fig. 8a). Nos kinzigitos do CS, ela mostra os maiores teores de $\mathrm{TiO}_{2}$ e $\mathrm{FeO}$, enquanto que a $\mathrm{X}_{\mathrm{Mg}}$ aumenta para os xistos da $\mathrm{BJ}$ e os paragnaisses não-granadíferos do CS. A correlação inversa entre $\mathrm{X}_{\mathrm{Mg}}$ e Ti (Fig. 8b) sugere a substituição $\left(\mathrm{Ti}^{+4}\right)^{\mathrm{VI}}+(\square)^{\mathrm{VI}} \Rightarrow 2\left(\mathrm{Mg}^{+2}\right)^{\mathrm{VI}}$ (Guidotti et al. 1977). Com efeito, os grãos com maiores $X_{\mathrm{Mg}}$ são aqueles parcialmente substituídos por fibrolita (Figs. 8a,b). Nos leucogranitos, a composição da biotita situase próxima do pólo anita (Fig. 8a). Os grãos que orlam nódulos de quartzo + fibrolita são os mais enriquecidos em $\mathrm{TiO}_{2}$ e $\mathrm{FeO}$, enquanto os parcialmente substituídos por fibrolita, em $\mathrm{MgO}$ (Tab. 2).

Feldspatos Nos kinzigitos do CS, os grãos de plagioclásio mostram núcleos de oligoclásio-andesina 
Tabela 1 - Análises químicas representativas da granada.

\begin{tabular}{|c|c|c|c|c|c|c|c|c|c|c|c|c|}
\hline Amostras & 138 & 138 & 023 & 023 & 20504 & 20504 & 20504 & 20504 & 29E5 & $29 \mathrm{E} 5$ & 53 & 53 \\
\hline Posição & $43 c \diamond$ & $44 \mathrm{~b} \diamond$ & $19 \mathrm{c} \diamond$ & $18 \mathrm{~b} \diamond$ & $27 \mathrm{c}$ & $28 \mathrm{~b}$ & $53 \mathrm{c}$ & $54 \mathrm{~b}$ & $06 \mathrm{cO}$ & $05 \mathrm{bO}$ & $64 \mathrm{cO}$ & $65 \mathrm{bO}$ \\
\hline $\mathrm{SiO}_{2}$ & 36,44 & 36,61 & 37,13 & 36,46 & 36,27 & 37,21 & 36,66 & 37,04 & 35,21 & 35,17 & 35,97 & 36,23 \\
\hline $\mathrm{TiO}_{2}$ & 0,05 & 0,00 & 0,00 & 0,02 & 0,03 & 0,01 & 0,03 & 0,03 & 0,000 & 0,060 & 0,000 & 0,010 \\
\hline $\mathrm{Al}_{2} \mathrm{O}_{3}$ & 20,54 & 20,43 & 21,02 & 20,88 & 20,58 & 20,80 & 21,15 & 21,01 & 20,78 & 20,44 & 20,56 & 20,73 \\
\hline $\mathrm{Cr}_{2} \mathrm{O}_{3}$ & 0,02 & 0,04 & 0,02 & 0,09 & 0,00 & 0,01 & 0,00 & 0,01 & 0,000 & 0,020 & 0,000 & 0,000 \\
\hline $\mathrm{Fe}_{2} \mathrm{O}_{3}$ & 1,83 & 1,53 & 0,72 & 1,14 & 3,01 & 2,31 & 3,59 & 3,53 & 3,260 & 3,190 & 1,970 & 1,640 \\
\hline $\mathrm{FeO}$ & 28,68 & 29,37 & 33,60 & 34,19 & 34,90 & 37,45 & 33,24 & 33,91 & 31,90 & 33,10 & 33,18 & 34,000 \\
\hline $\mathrm{MnO}$ & 8,34 & 8,51 & 3,18 & 3,82 & 0,12 & 0,19 & 0,05 & 0,08 & 6,760 & 6,110 & 5,810 & 5,750 \\
\hline $\mathrm{MgO}$ & 2,90 & 2,53 & 3,54 & 2,38 & 4,17 & 3,63 & 5,89 & 5,76 & 1,330 & 1,080 & 1,730 & 1,460 \\
\hline $\mathrm{CaO}$ & 0,95 & 0,79 & 0,92 & 0,98 & 0,21 & 0,05 & 0,00 & 0,00 & 0,640 & 0,620 & 0,580 & 0,690 \\
\hline $\mathrm{Na}_{2} \mathrm{O}$ & 0,02 & 0,06 & 0,02 & 0,01 & 0,09 & 0,04 & 0,01 & 0,00 & 0,030 & 0,020 & 0,030 & 0,000 \\
\hline $\mathrm{K}_{2} \mathrm{O}$ & 0,00 & 0,00 & 0,00 & 0,00 & 0,08 & 0,03 & 0,00 & 0,00 & 0,020 & 0,000 & 0,000 & 0,010 \\
\hline Total & 99,78 & 99,88 & 100,2 & 99,97 & 99,46 & 101,76 & 100,62 & 101,43 & 99,92 & 99,81 & 99,83 & 100,5 \\
\hline $\mathrm{Si}$ & 2,959 & 2,977 & 2,984 & 2,963 & 2,936 & 2,960 & 2,905 & 2,918 & 2,895 & 2,904 & 2,948 & 2,954 \\
\hline $\mathrm{Ti}$ & 0,003 & 0,000 & 0,000 & 0,001 & 0,002 & 0,001 & 0,002 & 0,002 & 0,000 & 0,004 & 0,000 & 0,001 \\
\hline $\mathrm{Al}$ & 1,966 & 1,958 & 1,991 & 1,999 & 1,964 & 1,950 & 1,975 & 1,951 & 2,014 & 1,989 & 1,986 & 1,991 \\
\hline $\mathrm{Cr}$ & 0,001 & 0,003 & 0,001 & 0,006 & 0,000 & 0,000 & 0,000 & 0,001 & 0,000 & 0,001 & 0,000 & 0,000 \\
\hline $\mathrm{Fe}^{3}$ & 0,112 & 0,094 & 0,043 & 0,070 & 0,183 & 0,138 & 0,214 & 0,209 & 0,202 & 0,198 & 0,122 & 0,101 \\
\hline $\mathrm{Fe}^{2}$ & 1,948 & 1,997 & 2,258 & 2,323 & 2,363 & 2,491 & 2,203 & 2,234 & 2,194 & 2,286 & 2,274 & 2,3189 \\
\hline $\mathrm{Mn}$ & 0,573 & 0,586 & 0,217 & 0,263 & 0,008 & 0,013 & 0,004 & 0,005 & 0,470 & 0,427 & 0,403 & 0,397 \\
\hline $\mathrm{Mg}$ & 0,351 & 0,307 & 0,424 & 0,289 & 0,504 & 0,430 & 0,696 & 0,676 & 0,163 & 0,132 & 0,212 & 0,178 \\
\hline $\mathrm{Ca}$ & 0,083 & 0,069 & 0,079 & 0,085 & 0,019 & 0,004 & 0,000 & 0,000 & 0,056 & 0,055 & 0,051 & 0,061 \\
\hline $\mathrm{Na}$ & 0,003 & 0,009 & 0,003 & 0,002 & 0,014 & 0,007 & 0,002 & 0,000 & 0,004 & 0,004 & 0,004 & 0,000 \\
\hline $\mathrm{K}$ & 0,000 & 0,000 & 0,000 & 0,000 & 0,009 & 0,004 & 0,000 & 0,000 & 0,002 & 0,000 & 0,000 & 0,001 \\
\hline Grossularia & 0,000 & 0,000 & 0,004 & 0,000 & 0,000 & 0,000 & 0,000 & 0,000 & 0,000 & 0,000 & 0,000 & 0,000 \\
\hline Almandina & 0,659 & 0,675 & 0,758 & 0,785 & 0,817 & 0,848 & 0,759 & 0,766 & 0,761 & 0,788 & 0,773 & 0,785 \\
\hline Piropo & 0,119 & 0,104 & 0,142 & 0,098 & 0,174 & 0,146 & 0,240 & 0,232 & 0,056 & 0,046 & 0,072 & 0,060 \\
\hline Espessartita & 0,194 & 0,198 & 0,073 & 0,089 & 0,003 & 0,004 & 0,001 & 0,002 & 0,163 & 0,147 & 0,137 & 0,134 \\
\hline Andradita & 0,028 & 0,023 & 0,022 & 0,029 & 0,006 & 0,001 & 0,000 & 0,000 & 0,020 & 0,019 & 0,017 & 0,021 \\
\hline $\mathrm{Al}\left({ }^{\mathrm{IV}}\right)$ & 0,041 & 0,023 & 0,016 & 0,037 & 0,064 & 0,040 & 0,095 & 0,082 & 0,105 & 0,096 & 0,052 & 0,046 \\
\hline $\mathrm{Al}\left({ }^{\mathrm{VI}}\right)$ & 1,925 & 1,936 & 1,975 & 1,962 & 1,900 & 1,910 & 1,880 & 1,869 & 1,909 & 1,893 & 1,934 & 1,945 \\
\hline $\mathrm{XMg}\left(\mathrm{Fe}^{2+}\right)$ & 0,153 & 0,133 & 0,158 & 0,111 & 0,176 & 0,147 & 0,240 & 0,232 & 0,069 & 0,055 & 0,085 & 0,071 \\
\hline $\mathrm{Fe}^{3+} /(\mathrm{FeT})$ & 0,054 & 0,045 & 0,019 & 0,029 & 0,072 & 0,053 & 0,089 & 0,086 & 0,084 & 0,080 & 0,051 & 0,042 \\
\hline $\mathrm{XMg}$ & 0,119 & 0,103 & 0,142 & 0,097 & 0,173 & 0,146 & 0,240 & 0,232 & 0,056 & 0,046 & 0,072 & 0,060 \\
\hline $\mathrm{XFe}\left({ }^{2+}\right)$ & 0,658 & 0,673 & 0,757 & 0,784 & 0,810 & 0,845 & 0,759 & 0,766 & 0,759 & 0,787 & 0,772 & 0,785 \\
\hline $\mathrm{XCa}$ & 0,028 & 0,023 & 0,027 & 0,029 & 0,006 & 0,001 & 0,000 & 0,000 & 0,019 & 0,019 & 0,017 & 0,021 \\
\hline XMn & 0,194 & 0,198 & 0,073 & 0,089 & 0,003 & 0,004 & 0,001 & 0,002 & 0,163 & 0,147 & 0,137 & 0,134 \\
\hline Cátions & 7 & 7 & 7 & 7 & 7 & 7 & 7 & 7 & 7 & 7 & 7 & 7 \\
\hline Oxigênios & 12 & 12 & 12 & 12 & 12 & 12 & 12 & 12 & 12 & 12 & 12 & 12 \\
\hline
\end{tabular}

c-centro; b-bordo. / $\diamond$ - Granada de kinzigitos do CS. / - Granada de xistos aluminosos da BJ. / O - Granada dos leucogranitos.

$\left(\mathrm{An}_{26-31}\right)$ e bordos de oligoclásio $\left(\mathrm{An}_{24-27}\right)$ (Tab. 3). Nos paragnaisses não-granadíferos do $\mathrm{CS}$, os grãos exibem composição de oligoclásio, quase albítica $\left(\mathrm{An}_{14-16}\right)$, entretanto aqueles parcialmente substituídos por fibrolita $\mathrm{e}$ os de mirmequita são enriquecidos em anortita $\left(\operatorname{An}_{22-30}\right)$
(Tab. 3). Nos xistos da BJ, o plagioclásio é oligoclásio quase albita $\left(\mathrm{An}_{12}\right)$ (Tab. 3). Nos leucogranitos, os núcleos dos grãos de plagioclásio e aqueles de mirmequita são oligoclásio $\left(\mathrm{An}_{12-16}-\mathrm{Ab}_{85-87}-\mathrm{Or}_{01}\right)$, enquanto que os bordos são albita $\left(\mathrm{An}_{01-02}-\mathrm{Ab}_{97-98}-\mathrm{Or}_{01}\right)(\mathrm{Tab} .3)$. Os 

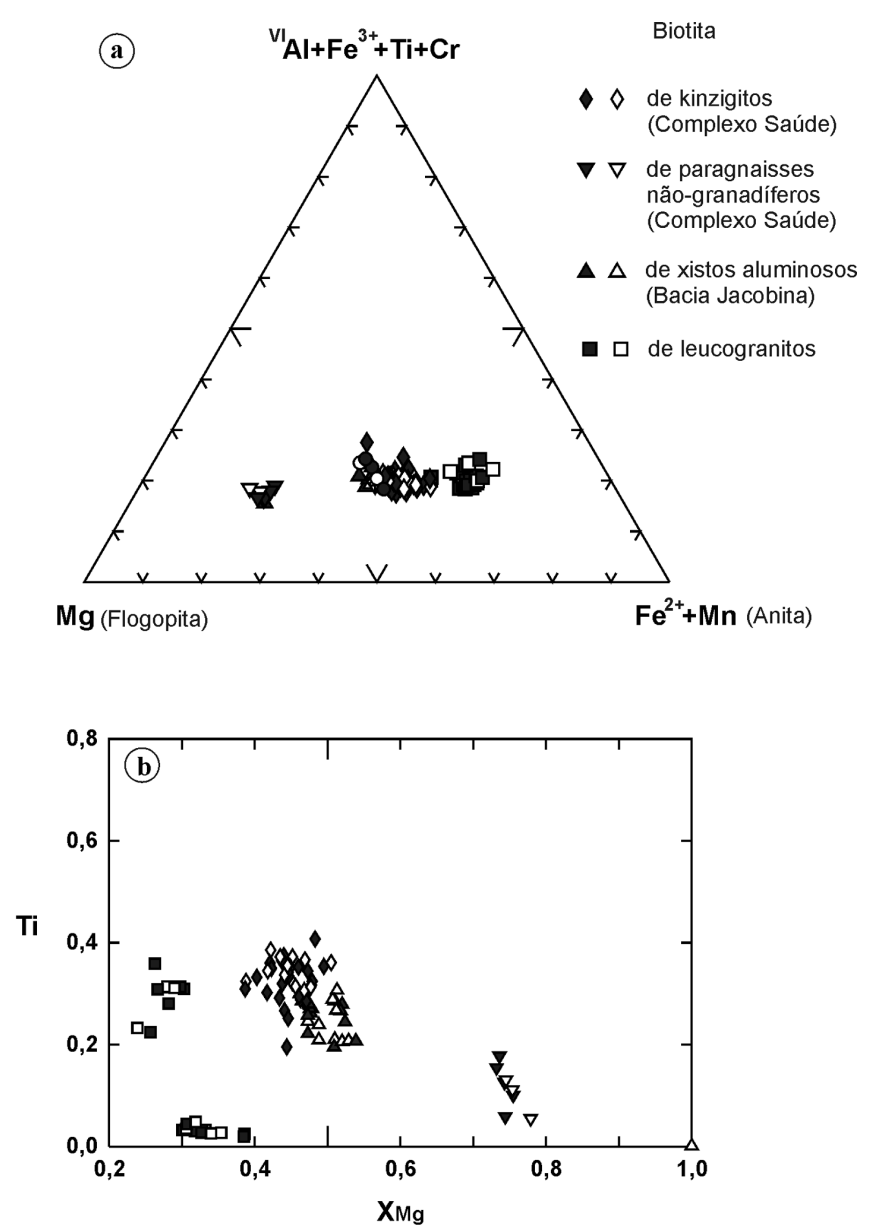

Figura 8 - Diagramas com a distribuição dos grãos de biotita estudados. (a) Diagrama ternário cationico $\left({ }^{V l} \mathrm{Al}+\mathrm{Fe}^{3+}+\mathrm{Ti}+\mathrm{Cr}\right)-\mathrm{Mg}-\left(\mathrm{Fe}^{2+}+\mathrm{Mn}\right)$ (a.p.f.u.) e (b) Diagrama binário $X_{M g} x$ Ti (a.p.f.u.) com a projeção da biotita das rochas investigadas. Símbolos preenchidos representam análises nos centros dos grãos e símbolos vazios nos seus bordos.

grãos de $\mathrm{K}$-feldspato são pertíticos $\left(\mathrm{An}_{00}-\mathrm{Ab}_{10-12}-\mathrm{Or}_{90 \text { - }}\right.$ ${ }_{88}$ ) com componente albita crescendo para os bordos $\left(\mathrm{An}_{00}-\mathrm{Ab}_{14-17}-\mathrm{Or}_{83-80}\right)$. A albita forma também grãos individuais com composição de $\mathrm{An}_{05-07}-\mathrm{Ab}_{94-95}-\mathrm{Or}_{00-01}$ (Tab. 3).

Estaurolita Nos xistos granadíferos da BJ, a estaurolita mostra zoneamento composicional com $\mathrm{Mg}$ e $\mathrm{Zn}$ decrescendo e Fe aumentando do centro para os bordos dos grãos (Tab. 4), conforme as substituições $\mathrm{Fe} \Leftrightarrow \mathrm{Mg}$ $\Leftrightarrow$ Zn (Holdaway et al. 1986). Quando a estaurolita está inclusa em andaluzita (xistos da BJ) ou em cordierita (paragnaisses do $\mathrm{CS}$ ), os teores de $\mathrm{FeO}$ e $\mathrm{MgO}$ são menores e ambos decrescem do centro para os bordos dos grãos (Tab. 4).

Cordierita A soma total dos componentes na cordierita está entre 95,92 e 97,85\% (Tab. 5), o que implica em conteúdo de fluidos entre 2 e $4 \%$. A razão $X_{\mathrm{Mg}}$ varia de 0,61 a 0,67 e a $X_{\mathrm{Fe}}$ entre 0,32 e 0,38 , excetuando os grãos parcialmente substituídos por fibrolita, caracte- rísticos dos paragnaisses do $\mathrm{CS}$, nos quais a $\mathrm{X}_{\mathrm{Mg}}$ é 0,86 e $\mathrm{X}_{\mathrm{Fe}}$ de 0,13 .

Muscovita A muscovita dos paragnaisses não-granadíferos do CS mostra composição entre a ferrimuscovita $\left[\mathrm{KFe}_{2}^{+3} \mathrm{AlSi}_{3} \mathrm{O}_{10}(\mathrm{OH})_{2}\right]$ e a celadonita $[\mathrm{K}(\mathrm{Mg}, \mathrm{Fe})$ $\left.\mathrm{AlSi}_{4} \mathrm{O}_{10}(\mathrm{OH})_{2}\right]$, destacando-se o empobrecimento em $\mathrm{Al}_{2} \mathrm{O}_{3}$ e $\mathrm{Na}_{2} \mathrm{O}$ e o enriquecimento em $\mathrm{FeO}$ e $\mathrm{MgO}$, em relaçã̃o àquela dos xistos da $\mathrm{BJ}$ (Tab. 6). Nesses últimos, a composição química envolve os componentes paragonita (rica em $\mathrm{Na}$ ), ferrimuscovita, celadonita e fucsita (rica em Ti e Cr). Nos paragnaisses do CS, os teores de $\mathrm{Al}$ decrescem dos centros para os bordos dos grãos, enquanto naqueles dos xistos da $\mathrm{BJ}, \mathrm{Al}$ e $\mathrm{Na}$ crescem e $\mathrm{Mg}$ decresce dos centros para os bordos da muscovita (Tab. 6). Nos leucogranitos, os raros grãos prismáticos de muscovita contêm teores de $\mathrm{TiO}_{2}$ acima de $0,80 \%$ (Tab. 6). Estes grãos e aqueles associados à biotita são enriquecidos em $\mathrm{MgO}$ e $\mathrm{FeO}$, em relação aos que substituem fibrolita (Tab. 6).

Cloritóide e Clorita O cloritóide contém teores de $\mathrm{MgO}$ e $\mathrm{FeO}$ próximos a 6,5\% e 22,50\%, respectivamente. Nos xistos da BJ, a clorita mostra composição química rica em $\mathrm{FeO}(\approx 22 \%)$ e $\mathrm{X}_{\mathrm{Mg}}$ variando entre $0,55 \mathrm{e}$ 0,58 .

\section{INTERPRETAÇÃO DAS MICROESTRUTURAS, REAÇÕES MINERAIS E EVOLUÇÃO $P$-T DO METAMORFISMO/ METASSOMATISMO As}

reações formadoras das assembléias minerais investigadas foram definidas com auxílio de grades petrogenéticas nos sistemas FMAS, FMASH e KFMASH $\left(\mathrm{K}_{2} \mathrm{O}, \mathrm{FeO}, \mathrm{MgO}, \mathrm{Al}_{2} \mathrm{O}_{3}, \mathrm{SiO}_{2}\right.$ e $\left.\mathrm{H}_{2} \mathrm{O}\right)$, disponíveis na literatura. Utilizou-se, também, o diagrama ternário AFM, projetado a partir da muscovita ou $\mathrm{K}$-feldspato e quartzo (Thompson, 1957), com vértices representados por: $\mathrm{A}=1 / 2\left[\left(\mathrm{Al}_{2} \mathrm{O}_{3}\right) / 2\right] ; \mathrm{F}=\mathrm{FeO}$ e $\mathrm{M}=\mathrm{MgO}$.

Microestruturas e reações minerais metamórficas Nos kinzigitos do CS, cordierita ao redor ou incluindo granada (Fig. 5b) e sillimanita indicam reação desenvolvida durante descompressão orogênica, onde granada e sillimanita, estáveis a pressões mais altas, foram desestabilizadas para cristalização da cordierita (e.g. Harris \& Holland 1984). O plagioclásio mostra as mesmas inclusões (Fig. 5a) sugerindo crescimento contemporâneo ao da cordierita. Vale acrescentar que se o plagioclásio cristalizou para acomodar o componente andradita da granada, a fonte de sódio poderia ser um líquido granítico, presente no sistema químico da reação. Considerando que a água pode estar presente em até $4 \%$ na cordierita, a seguinte reação divariante poderia ocorrer no sistema $(\mathrm{Na}) \mathrm{FMAS}(\mathrm{H})$ :

$$
\begin{aligned}
& \mathrm{Grt}+\mathrm{Sil}+\mathrm{Qtz}+(\mathrm{L}) \Rightarrow \mathrm{Crd}+(\mathrm{Pl}) \\
& (\text { modificado de Harris \& Holland 1984) }
\end{aligned}
$$

Nos paragnaisses não-granadíferos do CS, inclusões de estaurolita e sillimanita, em cordierita (Fig. 
Tabela 2 - Análises químicas representativas de biotita.

\begin{tabular}{|c|c|c|c|c|c|c|c|c|c|c|c|c|c|}
\hline Amostras & 138 & 138 & 024 & 024 & 012 & 074 & 073 & 073 & 56 & 56 & $29 \mathrm{E} 5$ & 29E5 & 29E4 \\
\hline Posição & $44 \mathrm{~b} \diamond$ & $45 c \diamond$ & $44 \mathrm{~b} \diamond$ & $45 c \diamond$ & $20 c \nabla$ & $17 \mathrm{c} \nabla$ & $08 \mathrm{~b} \Delta$ & $09 \mathrm{c} \Delta$ & $29 \mathrm{c}^{* *}$ & $30 b^{* *}$ & $03 \mathrm{c}+$ & $12 \mathrm{c}++$ & $16 \mathrm{c} \#$ \\
\hline $\mathrm{SiO}_{2}$ & 34,48 & 34,65 & 35,17 & 35,02 & 37,84 & 35,96 & 35,50 & 35,93 & 34,29 & 34,09 & 34,79 & 35,19 & 35,55 \\
\hline $\mathrm{TiO}_{2}$ & 2,970 & 2,550 & 2,740 & 2,910 & 1,550 & 1,790 & 2,660 & 2,440 & 2,640 & 2,620 & 0,260 & 0,170 & 3,218 \\
\hline $\mathrm{Al}_{2} \mathrm{O}_{3}$ & 18,02 & 18,80 & 19,41 & 19,14 & 18,97 & 18,76 & 18,60 & 19,28 & 18,66 & 18,01 & 20,04 & 20,46 & 18,15 \\
\hline $\mathrm{Cr}_{2} \mathrm{O}_{3}$ & 0,140 & 0,150 & 0,100 & 0,140 & 0,060 & 0,000 & 0,130 & 0,130 & 0,030 & 0,000 & 0,010 & 0,020 & 0,050 \\
\hline $\mathrm{Fe}_{2} \mathrm{O}_{3}$ & 1,460 & 0,000 & 0,000 & 0,000 & 0,000 & 0,000 & 0,000 & 0,000 & 0,000 & 0,000 & 0,000 & 0,000 & 0,000 \\
\hline $\mathrm{FeO}$ & 19,61 & 19,77 & 19,03 & 19,60 & 10,16 & 17,86 & 17,90 & 17,25 & 24,44 & 24,45 & 24,05 & 21,57 & 22,24 \\
\hline $\mathrm{MnO}$ & 0,150 & 0,190 & 0,240 & 0,200 & 0,890 & 0,100 & 0,090 & 0,060 & 0,160 & 0,160 & 0,150 & 0,130 & 0,226 \\
\hline $\mathrm{MgO}$ & 8,680 & 8,640 & 8,970 & 8,880 & 15,89 & 10,90 & 10,59 & 10,48 & 5,330 & 5,330 & 6,310 & 7,570 & 6,876 \\
\hline $\mathrm{CaO}$ & 0,010 & 0,030 & 0,050 & 0,040 & 0,010 & 0,000 & 0,050 & 0,000 & 0,000 & 0,010 & 0,040 & 0,010 & 0,015 \\
\hline $\mathrm{Na}_{2} \mathrm{O}$ & 0,180 & 0,120 & 0,080 & 0,090 & 0,140 & 0,250 & 0,240 & 0,300 & 0,080 & 0,110 & 0,040 & 0,170 & 0,050 \\
\hline $\mathrm{K}_{2} \mathrm{O}$ & 9,450 & 9,250 & 9,940 & 9,750 & 9,440 & 9,150 & 8,470 & 8,830 & 9,630 & 9,820 & 9,730 & 9,570 & 9,982 \\
\hline Total & 95,14 & 94,16 & 95,72 & 95,78 & 95,04 & 94,79 & 94,26 & 94,75 & 95,25 & 94,59 & 95,40 & 94,86 & 96,35 \\
\hline $\mathrm{Si}$ & 5,313 & 5,370 & 5,369 & 5,336 & 5,543 & 5,470 & 5,449 & 5,467 & 5,407 & 5,436 & 5,424 & 5,437 & 5,449 \\
\hline $\mathrm{Ti}$ & 0,344 & 0,297 & 0,314 & 0,334 & 0,171 & 0,205 & 0,307 & 0,279 & 0,313 & 0,314 & 0,030 & 0,020 & 0,371 \\
\hline $\mathrm{Al}$ & 3,272 & 3,433 & 3,491 & 3,438 & 3,275 & 3,364 & 3,363 & 3,458 & 3,467 & 3,386 & 3,683 & 3,726 & 3,278 \\
\hline $\mathrm{Cr}$ & 0,017 & 0,019 & 0,011 & 0,017 & 0,007 & 0,001 & 0,016 & 0,016 & 0,003 & 0,000 & 0,001 & 0,002 & 0,006 \\
\hline $\mathrm{Fe}^{3}$ & 0,170 & 0,000 & 0,000 & 0,000 & 0,000 & 0,000 & 0,000 & 0,000 & 0,000 & 0,000 & 0,000 & 0,000 & 0,000 \\
\hline $\mathrm{Fe}^{2}$ & 2,527 & 2,562 & 2,429 & 2,498 & 1,245 & 2,272 & 2,297 & 2,195 & 3,222 & 3,261 & 3,136 & 2,787 & 2,850 \\
\hline $\mathrm{Mn}$ & 0,019 & 0,026 & 0,031 & 0,026 & 0,110 & 0,013 & 0,012 & 0,008 & 0,021 & 0,021 & 0,020 & 0,017 & 0,029 \\
\hline $\mathrm{Mg}$ & 1,994 & 1,996 & 2,040 & 2,016 & 3,469 & 2,471 & 2,423 & 2,377 & 1,254 & 1,268 & 1,466 & 1,743 & 1,570 \\
\hline $\mathrm{Ca}$ & 0,002 & 0,004 & 0,008 & 0,007 & 0,002 & 0,000 & 0,009 & 0,000 & 0,000 & 0,001 & 0,007 & 0,002 & 0,002 \\
\hline $\mathrm{Na}$ & 0,056 & 0,036 & 0,025 & 0,026 & 0,040 & 0,073 & 0,071 & 0,089 & 0,024 & 0,035 & 0,012 & 0,051 & 0,015 \\
\hline $\mathrm{K}$ & 1,857 & 1,828 & 1,935 & 1,896 & 1,763 & 1,776 & 1,659 & 1,715 & 1,936 & 1,997 & 1,936 & 1,886 & 1,951 \\
\hline $\mathrm{XMg}\left(\mathrm{Fe}^{2+}\right)$ & 0,441 & 0,438 & 0,456 & 0,447 & 0,736 & 0,521 & 0,513 & 0,520 & 0,280 & 0,280 & 0,318 & 0,385 & 0,355 \\
\hline $\mathrm{XFe}\left({ }^{2+}\right)$ & 0,557 & 0,559 & 0,540 & 0,550 & 0,258 & 0,478 & 0,485 & 0,479 & 0,717 & 0,717 & 0,678 & 0,613 & 0,644 \\
\hline $\mathrm{Al}\left({ }^{\mathrm{IV}}\right)$ & 2,688 & 2,630 & 2,632 & 2,664 & 2,458 & 2,530 & 2,551 & 2,533 & 2,593 & 2,564 & 2,576 & 2,563 & 2,551 \\
\hline $\mathrm{Al}\left({ }^{\mathrm{VI}}\right)$ & 0,584 & 0,802 & 0,860 & 0,674 & 0,818 & 0,834 & 0,812 & 0,925 & 0,874 & 0,823 & 1,108 & 1,163 & 0,727 \\
\hline Cátions & 15,570 & 15,572 & 15,654 & 15,594 & 15,626 & 15,644 & 15,608 & 15,608 & 15,647 & 15,719 & 15,985 & 15,671 & 15,521 \\
\hline Oxigênios & 22 & 22 & 22 & 22 & 22 & 22 & 22 & 22 & 22 & 22 & 22 & 22 & 22 \\
\hline
\end{tabular}

c-centro; b-bordo;

\section{Rochas metassedimentares}

$\diamond$ - biotita de kinzigito do CS;

$\nabla$ - biotita de paragnaisse não-granadífero

do CS;

$\Delta$ - biotita de xisto aluminoso da BJ.

\section{Leucogranitos}

** - biotita marrom avermelhada na matriz dos fenoclastos de feldspato;

+ - biotita esverdeada parcialmente transformada em clorita e em contato com granada;

++ - biotita parda parcialmente transformada em fibrolita nos nódulos;

\# - biotita marrom escura na margem de nódulo de quartzo + fibrolita. 5c), constituem restos da assembléia mineralógica, pretérita, de média pressão e média temperatura, da fácies anfibolito (e.g. Spear 1993). Cordierita indica condições de baixa pressão e alta temperatura. Considerando que biotita ocorre em um amplo espectro de temperatura e pressão, a assembléia cordierita + estaurolita + biotita + sillimanita não representa uma associação em equilíbrio metamórfico, o que é confirmado no diagrama AFM de Thompson (1957), onde a linha de conexão entre sillimanita e biotita corta aquela entre estaurolita e cordierita (Fig. 9).

Nas grades petrogenéticas de Spear \& Cheney (1989) e Pattison et al. (1999), estaurolita, sillimanita e cordierita são formadas, segundo uma seqüência de três reações no sistema KFMASH:

$$
\begin{aligned}
& \mathrm{Ms}+\mathrm{Chl} \Rightarrow \mathrm{St}+\mathrm{Bt}+\mathrm{Qtz}+\mathrm{H}_{2} \mathrm{O} \\
& \mathrm{Ms}+\mathrm{St}+\mathrm{Chl}+\mathrm{Qtz} \Rightarrow \mathrm{Sil}+\mathrm{Bt}+\mathrm{H}_{2} \mathrm{O}
\end{aligned}
$$


Tabela 3 - Análises químicas representativas dos feldspatos.

\begin{tabular}{|c|c|c|c|c|c|c|c|c|c|c|c|c|c|}
\hline Amostras & 024 & 024 & 012 & 012 & 012 & 012 & 082 & $29 \mathrm{E} 4$ & $29 \mathrm{E} 4$ & $29 \mathrm{E} 4$ & $29 \mathrm{E} 4$ & 56 & 56 \\
\hline Posição & $32 c^{*}$ & $31 b^{*}$ & $45 c^{*}$ & $44 b^{*}$ & $05=$ & 02\# & $02 c^{*}$ & $02 c^{* *}$ & $03 \mathrm{~b} * *$ & $07 c \diamond$ & $08 \mathrm{~b} \diamond$ & $18 \mathrm{c} \bullet$ & $17 b \bullet$ \\
\hline $\mathrm{SiO}_{2}$ & 61,45 & 61,28 & 61,10 & 60,89 & 47,41 & 61,88 & 65,57 & 65,28 & 68,28 & 64,30 & 64,82 & 66,88 & 68,06 \\
\hline $\mathrm{TiO}_{2}$ & 0,00 & 0,04 & 0,02 & 0,00 & 0,00 & 0,00 & 0,03 & 0,020 & 0,010 & 0,000 & 0,020 & 0,000 & 0,000 \\
\hline $\mathrm{Al}_{2} \mathrm{O}_{3}$ & 23,65 & 24,39 & 24,07 & 24,14 & 45,39 & 23,20 & 21,43 & 22,09 & 19,51 & 18,75 & 18,42 & 20,17 & 19,63 \\
\hline $\mathrm{Cr}_{2} \mathrm{O}_{3}$ & 0,00 & 0,02 & 0,01 & 0,00 & 0,00 & 0,00 & 0,01 & 0,000 & 0,020 & 0,000 & 0,000 & 0,040 & 0,000 \\
\hline $\mathrm{Fe}_{2} \mathrm{O}_{3}$ & 0,05 & 0,14 & 0,00 & 0,08 & 0,00 & 0,01 & 0,04 & 0,010 & 0,020 & 0,040 & 0,070 & 0,000 & 0,000 \\
\hline $\mathrm{FeO}$ & 0,00 & 0,00 & 0,02 & 0,00 & 0,37 & 0,00 & 0,00 & 0,000 & 0,000 & 0,000 & 0,000 & 0,000 & 0,020 \\
\hline $\mathrm{MnO}$ & 0,00 & 0,08 & 0,05 & 0,02 & 0,01 & 0,03 & 0,00 & 0,000 & 0,000 & 0,000 & 0,000 & 0,000 & 0,000 \\
\hline $\mathrm{MgO}$ & 0,00 & 0,00 & 0,00 & 0,01 & 0,00 & 0,00 & 0,01 & 0,010 & 0,000 & 0,000 & 0,000 & 0,000 & 0,030 \\
\hline $\mathrm{CaO}$ & 5,51 & 5,79 & 5,69 & 5,90 & 2,74 & 4,74 & 2,60 & 3,050 & 0,270 & 0,040 & 0,090 & 1,140 & 0,420 \\
\hline $\mathrm{Na}_{2} \mathrm{O}$ & 8,49 & 8,50 & 8,35 & 8,28 & 3,54 & 8,90 & 10,36 & 10,25 & 11,72 & 1,110 & 1,930 & 11,20 & 11,39 \\
\hline $\mathrm{K}_{2} \mathrm{O}$ & 0,15 & 0,13 & 0,06 & 0,06 & 0,07 & 0,21 & 0,05 & 0,150 & 0,170 & 15,55 & 14,82 & 0,070 & 0,110 \\
\hline Total & 99,30 & 100,4 & 99,37 & 99,38 & 99,53 & 98,97 & 100,10 & 100,9 & 99,99 & 99,80 & 100,2 & 99,50 & 99,66 \\
\hline $\mathrm{Si}$ & 2,746 & 2,709 & 2,730 & 2,721 & 2,134 & 2,766 & 2,880 & 2,846 & 2,981 & 2,964 & 2,964 & 2,941 & 2,987 \\
\hline $\mathrm{Ti}$ & 0,000 & 0,001 & 0,001 & 0,000 & 0,000 & 0,000 & 0,001 & 0,001 & 0,000 & 0,000 & 0,001 & 0,000 & 0,000 \\
\hline $\mathrm{Al}$ & 1,245 & 1,271 & 1,267 & 1,272 & 2,408 & 1,222 & 1,109 & 1,135 & 1,004 & 1,019 & 0,993 & 1,045 & 1,015 \\
\hline $\mathrm{Cr}$ & 0,000 & 0,001 & 0,000 & 0,000 & 0,000 & 0,000 & 0,000 & 0,000 & 0,001 & 0,000 & 0,000 & 0,001 & 0,000 \\
\hline $\mathrm{Fe}^{3}$ & 0,002 & 0,005 & 0,000 & 0,003 & 0,000 & 0,000 & 0,001 & 0,000 & 0,001 & 0,002 & 0,002 & 0,000 & 0,000 \\
\hline $\mathrm{Fe}^{2}$ & 0,000 & 0,000 & 0,001 & 0,000 & 0,014 & 0,000 & 0,000 & 0,000 & 0,000 & 0,000 & 0,000 & 0,000 & 0,001 \\
\hline $\mathrm{Mn}$ & 0,000 & 0,003 & 0,002 & 0,001 & 0,000 & 0,001 & 0,000 & 0,000 & 0,000 & 0,000 & 0,000 & 0,000 & 0,000 \\
\hline $\mathrm{Mg}$ & 0,000 & 0,000 & 0,000 & 0,001 & 0,000 & 0,000 & 0,001 & 0,001 & 0,000 & 0,000 & 0,000 & 0,000 & 0,002 \\
\hline $\mathrm{Ca}$ & 0,264 & 0,274 & 0,272 & 0,282 & 0,132 & 0,227 & 0,122 & 0,143 & 0,013 & 0,002 & 0,004 & 0,054 & 0,020 \\
\hline $\mathrm{Na}$ & 0,735 & 0,729 & 0,724 & 0,718 & 0,308 & 0,771 & 0,882 & 0,866 & 0,992 & 0,099 & 0,171 & 0,955 & 0,969 \\
\hline $\mathrm{K}$ & 0,009 & 0,007 & 0,003 & 0,003 & 0,004 & 0,012 & 0,003 & 0,008 & 0,009 & 0,915 & 0,864 & 0,004 & 0,006 \\
\hline Cátions & 5 & 5 & 5 & 5 & 5 & 5 & 5 & 5 & 5 & 5 & 5 & 5 & 5 \\
\hline Oxigênios & 8 & 8 & 8 & 8 & 8 & 8 & 8 & 8 & 8 & 8 & 8 & 8 & 8 \\
\hline Anortita & 0,262 & 0,271 & 0,272 & 0,281 & 0,298 & 0,225 & 0,121 & 0,140 & 0,013 & 0,002 & 0,004 & 0,053 & 0,020 \\
\hline Albita & 0,730 & 0,721 & 0,724 & 0,715 & 0,694 & 0,763 & 0,876 & 0,851 & 0,978 & 0,097 & 0,165 & 0,943 & 0,974 \\
\hline Ortoclásio & 0,009 & 0,007 & 0,003 & 0,003 & 0,009 & 0,012 & 0,003 & 0,008 & 0,009 & 0,901 & 0,831 & 0,004 & 0,006 \\
\hline
\end{tabular}

c-centro; b-bordo.

Rochas metassedimentares: kinzigitos (amostras 17 e 24) do CS; paragnaisses não-granadíferos (amostra 12) do CS; xisto aluminoso (amostra 82) da BJ.

* - plagioclásio; = - plagioclásio parcialmente substituído por fibrolita; \# - fase hospedeira de plagioclásio em mirmequita.

Leucogranitos: amostras 29E4 e 56.

** - plagioclásio; $\diamond$ - pertita; • - albita.

$$
\mathrm{e} \mathrm{Ms}+\mathrm{Chl}+\mathrm{Qtz} \Rightarrow \mathrm{Crd}+\mathrm{Sil}+\mathrm{Bt}+\mathrm{H}_{2} \mathrm{O}
$$

Essas reações pressupõem excesso de clorita e muscovita na assembléia mineralógica inicial, entretanto como há ausência de relictos desses minerais, nas amostras investigadas, pode-se supor que foram consumidos totalmente durante a seqüência dessas reações.

No estaurolita-granada-clorita-xisto da BJ, inclusões de cloritóide e quartzo na granada (Fig. 6b) sugerem a seguinte reação univariante, no sistema FMASH:

$\mathrm{Ctd}+\mathrm{Qtz} \Rightarrow \mathrm{Grt}+\mathrm{St}+\mathrm{Chl}+\mathrm{H}_{2} \mathrm{O}$
(Spear \& Cheney 1989)

Sabe-se que $\mathrm{CaO}$ e/ ou $\mathrm{MnO}$ estabilizam a granada a temperaturas próximas de $500^{\circ} \mathrm{C}$ (Spear,1993). Entretanto a granada desse xisto é pobre nos componentes espessartita, andradita e grossularia (Tab. 1). Porém, a presença de dolomita nas bordas da granada (Fig. 6a) sugere que os componentes andradita e grossularia foram usados para cristalização desse mineral. Adiciona-se o fato que a cristalização de dolomita, a partir da granada, ocorre quando há aumento da fugacidade de $\mathrm{CO}_{2}$ e formação de clorita, através da seguinte reação (Spear 1993): 
Tabela 4 - Análises químicas representativas de estaurolita.

\begin{tabular}{|c|c|c|c|c|c|c|c|}
\hline Amostras & 074 & 074 & 082 & 082 & 20504 & 20504 & 20504 \\
\hline Posição & A06c & $\mathrm{A} 15 \mathrm{c}$ & A71c & $\mathrm{A} 73 \mathrm{~b}$ & $\mathrm{~A} 15 \mathrm{c}$ & $\mathrm{A} 18 \mathrm{c}$ & A19b \\
\hline $\mathrm{SiO}_{2}$ & 26,47 & 28,53 & 27,72 & 27,64 & 27,39 & 26,50 & 27,31 \\
\hline $\mathrm{TiO}_{2}$ & 0,809 & 0,892 & 0,622 & 0,679 & 0,469 & 0,514 & 0,519 \\
\hline $\mathrm{Al}_{2} \mathrm{O}_{3}$ & 53,07 & 54,03 & 53,86 & 54,29 & 52,56 & 53,51 & 53,76 \\
\hline $\mathrm{Cr}_{2} \mathrm{O}_{3}$ & 0,010 & 0,058 & 0,349 & 0,286 & 0,000 & 0,029 & 0,034 \\
\hline $\mathrm{FeO}$ & 14,39 & 13,96 & 13,10 & 12,74 & 14,97 & 14,52 & 14,58 \\
\hline $\mathrm{MnO}$ & 0,420 & 0,296 & 0,345 & 0,325 & 0,000 & 0,026 & 0,014 \\
\hline $\mathrm{MgO}$ & 2,112 & 2,169 & 1,597 & 1,547 & 2,348 & 2,472 & 1,902 \\
\hline $\mathrm{CaO}$ & 0,000 & 0,018 & 0,000 & 0,000 & 0,006 & 0,000 & 0,022 \\
\hline $\mathrm{ZnO}$ & n.a. & n.a. & n.a. & n.a. & 0,358 & 0,295 & 0,224 \\
\hline $\mathrm{Na}_{2} \mathrm{O}$ & 0,008 & 0,011 & 0,028 & 0,070 & 0,020 & 0,015 & 0,043 \\
\hline $\mathrm{K}_{2} \mathrm{O}$ & 0,016 & 0,000 & 0,005 & 0,008 & 0,000 & 0,000 & 0,016 \\
\hline Total & 97,30 & 99,97 & 97,62 & 97,57 & 98,12 & 97,88 & 98,43 \\
\hline $\mathrm{Si}$ & 7,446 & 7,759 & 7,697 & 7,663 & 7,649 & 7,411 & 7,580 \\
\hline $\mathrm{Ti}$ & 0,171 & 0,182 & 0,130 & 0,142 & 0,098 & 0,108 & 0,108 \\
\hline $\mathrm{Al}$ & 17,59 & 17,31 & 17,63 & 17,74 & 17,30 & 17,64 & 17,58 \\
\hline $\mathrm{Cr}$ & 0,002 & 0,012 & 0,077 & 0,063 & 0,000 & 0,006 & 0,007 \\
\hline $\mathrm{Fe}^{2}$ & 3,384 & 3,175 & 3,042 & 2,953 & 3,495 & 3,396 & 3,383 \\
\hline $\mathrm{Mn}$ & 0,100 & 0,068 & 0,081 & 0,076 & 0,000 & 0,006 & 0,003 \\
\hline $\mathrm{Mg}$ & 0,885 & 0,879 & 0,661 & 0,639 & 0,977 & 1,030 & 0,787 \\
\hline $\mathrm{Ca}$ & 0,000 & 0,005 & 0,000 & 0,000 & 0,002 & 0,000 & 0,007 \\
\hline $\mathrm{Zn}$ & - & - & - & - & 0,074 & 0,061 & 0,046 \\
\hline $\mathrm{Na}$ & 0,004 & 0,006 & 0,015 & 0,038 & 0,011 & 0,008 & 0,023 \\
\hline $\mathrm{K}$ & 0,006 & 0,000 & 0,002 & 0,003 & 0,000 & 0,000 & 0,006 \\
\hline $\mathrm{XMg}\left(\mathrm{Fe}^{+2}\right)$ & 20,74 & 21,69 & 17,85 & 17,80 & 21,85 & 23,28 & 18,87 \\
\hline Cátions & 29,59 & 29,40 & 29,33 & 29,31 & 29,61 & 29,66 & 29,53 \\
\hline Oxigênios & 46 & 46 & 46 & 46 & 46 & 46 & 46 \\
\hline
\end{tabular}

c-centro; b-bordo; n.a.-não analisado; 074 - paragnaisse não-granadífero do CS; 082 - andaluzita-xisto da BJ; 20504 - estaurolita-granada-clorita-xisto da BJ

$$
\mathrm{Grt}+\mathrm{CO}_{2}+\mathrm{H} 2 \mathrm{O} \Rightarrow \mathrm{Chl}+\mathrm{Dol}
$$

No sillimanita-andaluzita-xisto da BJ, estaurolita inclusa em andaluzita (Fig. 6e) indica relicto de assembléia mineralógica pretérita formada em condições de média temperatura e média pressão que foi desestabilizada por queda da pressão, segundo a seguinte reação univariante no sistema KFMASH:

$$
\begin{aligned}
& \mathrm{Ms}+\mathrm{St}+\mathrm{Chl}+\mathrm{Qtz} \Rightarrow \text { And }+\mathrm{Bt}+\mathrm{H}_{2} \mathrm{O} \\
& (\text { Spear \& Cheney 1989) }
\end{aligned}
$$

Microestruturas e reações minerais metassomáticas Na literatura, a cristalização da fibrolita, formando microestruturas semelhantes às encontradas na área de estudo (Figs. 5d,e,f; 6d) é interpretada a partir da circulação de fluidos ácidos e redutores que lixiviam cátions-base de silicatos pré-existentes por aumento da $a_{\mathrm{H}^{+}}$(atividade iônica do hidrogênio) (e. g. Vernon
1979). No leucogranito Saracura, os nódulos de quartzo + fibrolita contêm biotita límpida $\left(\mathrm{Bt}_{2}\right)$ nos seus bordos e biotita substituída $\left(\mathrm{Bt}_{1}\right)$ por fibrolita nos seus núcleos (Fig. 7b). Para Foster (1977), a formação das auréolas ricas em biotita, em nódulos presentes nos ortognaisses do Maine, EUA, envolveria a dissolução simultânea da biotita localizada nos núcleos. Este processo de conservação mineralógica requer mobilidade de alumínio no fluido, o que pode ocorrer na forma de complexos iônicos com razão molar álcali/ alumínio semelhante àquela encontrada no feldspato alcalino (Kerrick 1988). A formação desses nódulos envolveria as seguintes reações ( $\mathrm{a}, \mathrm{b}, \mathrm{x}, \mathrm{y}=$ coeficientes estequiométricos), ao longo de corredores de cisalhamento e entre sítios de gradientes de tensão (Leite 2002, Leite et al. 2005).

\section{NÚCLEO DO NÓDULO}

$$
\left.\mathrm{K}_{2}\left(\mathrm{Mg}_{\mathrm{x}}, \mathrm{Fe}_{\mathrm{y}}\right)_{4}\left(\mathrm{Fe}_{\mathrm{Bt}}^{+3}, \mathrm{Al}_{\mathrm{b}}, \mathrm{Ti}_{\mathrm{c}}\right)_{2}\left[\mathrm{Si}_{6} \mathrm{Al}_{2} \mathrm{O}_{20}\right](\mathrm{OH}, \mathrm{F})_{4}+10 \mathrm{H}+\mathrm{ff}_{\mathrm{f}}\right) \Rightarrow
$$


Tabela 5 - Análises químicas representativas de cordierita.

\begin{tabular}{|c|c|c|c|c|c|c|c|}
\hline Amostras & $138^{*}$ & $138^{*}$ & $017^{*}$ & $023^{*}$ & $074+$ & $012 * *$ & $012 * *$ \\
\hline Posição & $40 \mathrm{c}$ & $41 b$ & $17 \mathrm{c}$ & $\mathrm{A} 59 \mathrm{c}$ & A20c & $\mathrm{A} 34 \mathrm{c}$ & $\mathrm{A} 38 \mathrm{c}$ \\
\hline $\mathrm{SiO}_{2}$ & 48,18 & 47,83 & 47,98 & 48,48 & 48,33 & 49,21 & 48,29 \\
\hline $\mathrm{TiO}_{2}$ & 0,015 & 0,020 & 0,002 & 0,000 & 0,000 & 0,002 & 0,062 \\
\hline $\mathrm{Al}_{2} \mathrm{O}_{3}$ & 32,08 & 31,76 & 32,61 & 32,402 & 32,34 & 33,46 & 32,29 \\
\hline $\mathrm{Cr}_{2} \mathrm{O}_{3}$ & 0,025 & 0,000 & 0,003 & 0,001 & 0,000 & 0,000 & 0,035 \\
\hline $\mathrm{FeO}$ & 8,408 & 7,289 & 7,986 & 8,763 & 7,345 & 3,054 & 2,988 \\
\hline $\mathrm{MnO}$ & 0,618 & 0,374 & 0,588 & 0,314 & 0,309 & 1,157 & 1,520 \\
\hline $\mathrm{MgO}$ & 7,833 & 7,655 & 8,146 & 7,712 & 8,370 & 10,55 & 10,24 \\
\hline $\mathrm{CaO}$ & 0,011 & 0,029 & 0,036 & 0,010 & 0,008 & 0,000 & 0,001 \\
\hline $\mathrm{Na}_{2} \mathrm{O}$ & 0,319 & 0,547 & 0,185 & 0,129 & 0,491 & 0,394 & 0,499 \\
\hline $\mathrm{K}_{2} \mathrm{O}$ & 0,054 & 0,961 & 0,022 & 0,005 & 0,000 & 0,022 & 0,000 \\
\hline Total & 97,55 & 96,47 & 97,56 & 97,80 & 97,19 & 97,85 & 95,92 \\
\hline $\mathrm{Si}$ & 5,021 & 5,040 & 4,988 & 5,031 & 5,023 & 4,998 & 5,015 \\
\hline $\mathrm{Ti}$ & 0,001 & 0,002 & 0,000 & 0,000 & 0,000 & 0,000 & 0,005 \\
\hline $\mathrm{Al}$ & 3,940 & 3,944 & 3,995 & 3,963 & 3,961 & 4,005 & 3,952 \\
\hline $\mathrm{Cr}$ & 0,002 & 0,000 & 0,000 & 0,000 & 0,000 & 0,000 & 0,003 \\
\hline $\mathrm{Fe}^{2}$ & 0,733 & 0,642 & 0,694 & 0,760 & 0,638 & 0,259 & 0,259 \\
\hline $\mathrm{Mn}$ & 0,055 & 0,033 & 0,052 & 0,028 & 0,027 & 0,100 & 0,134 \\
\hline $\mathrm{Mg}$ & 1,217 & 1,202 & 1,262 & 1,193 & 1,297 & 1,597 & 1,585 \\
\hline $\mathrm{Ca}$ & 0,001 & 0,003 & 0,004 & 0,000 & 0,001 & 0,000 & 0,000 \\
\hline $\mathrm{Na}$ & 0,064 & 0,112 & 0,037 & 0,026 & 0,099 & 0,078 & 0,100 \\
\hline K & 0,007 & 0,129 & 0,003 & 0,001 & 0,000 & 0,003 & 0,000 \\
\hline $\mathrm{XMg}\left(\mathrm{Fe}^{2+}\right)$ & 0,624 & 0,652 & 0,645 & 0,611 & 0,670 & 0,861 & 0,859 \\
\hline $\mathrm{XFe}\left({ }^{2+}\right)$ & 0,366 & 0,342 & 0,346 & 0,384 & 0,325 & 0,132 & 0,131 \\
\hline Oxigênios & 18 & 18 & 18 & 18 & 18 & 18 & 18 \\
\hline
\end{tabular}

c-centro; b-bordo.

* - grão em contato com granada, em kinzigito do CS; +- grão em paragnaisse não-granadífero do CS situado à oeste da cidade de Jacobina;

** - grão parcialmente substituído por fibrolita, em paragnaisse não-granadífero do CS.

$\Rightarrow \quad \mathrm{Al}_{2} \mathrm{SiO}_{5}+2 \mathrm{SiO}_{2}+5 \mathrm{H}_{2} \mathrm{O}+2\left[\mathrm{KAl}_{\mathrm{b}}(\mathrm{OH}, \mathrm{F})_{4} \cdot 3 \mathrm{SiO}_{2}\right]\left(\mathrm{H}_{\mathrm{A}}\right)+$ Sill (Fib) Qtz

$+4\left(\mathrm{Mg}_{\mathrm{x}}, \mathrm{Fe}_{\mathrm{y}}^{+2}\right)_{(\mathrm{ff})}+2\left(\mathrm{Fe}_{\mathrm{a}}^{+3}, \mathrm{Ti}^{+4} \mathrm{c}_{(\mathrm{fl})}\right.$

\section{BORDO DO NÓDULO}

$2\left[\mathrm{KAl}_{b}(\mathrm{OH}, \mathrm{F})_{4} \cdot 3 \mathrm{SiO}_{2}\right]_{(\mathrm{fl})}+4\left(\mathrm{Mg}_{\mathrm{x}}, \mathrm{Fe}_{\mathrm{y}}^{+2}\right)_{(\mathrm{ff})}+2\left(\mathrm{Fe}_{\mathrm{a}}^{+3}, \mathrm{Ti}^{+4} \mathrm{c}\right)+$ $8 \mathrm{H}_{2} \mathrm{O} \Rightarrow \mathrm{K}_{2}\left(\mathrm{Mg}_{\mathrm{x}}, \mathrm{Fe}_{\mathrm{y}}\right)_{4}\left(\mathrm{Fe}^{+3}, \mathrm{Al}_{\mathrm{b}}, \mathrm{Ti}_{\mathrm{c}}\right)_{2}\left[\mathrm{Si}_{6} \mathrm{Al}_{2} \mathrm{O}_{20}\right](\mathrm{OH}, \mathrm{F})_{4}+$ $16 \mathrm{H}^{+}$

$\mathrm{Bt}_{2}$

Três aspectos são importantes nessas reações iônicas: (i) a quebra da biotita $\left(\mathrm{Bt}_{1}\right)$ ocorreria em sítio de alta $a_{\mathrm{H}+}$ (núcleo do nódulo), mas geraria $\mathrm{H}_{2} \mathrm{O}$ para o fluido; (ii) a cristalização da biotita $\left(\mathrm{Bt}_{2}\right)$ se daria por aumento da $f_{\text {н2о }}$ (bordo do nódulo), estabelecendo, assim, um gradiente de potencial químico entre os dois sítios e; (iii) a cristalização da biotita $\left(\mathrm{Bt}_{2}\right)$ geraria mais íons de hidrogênio no fluido que migraria para lixiviar outros grãos de $\mathrm{Bt}_{1}$. $\mathrm{A} \mathrm{Bt}_{2}$ se mostra enriquecida em
$\mathrm{TiO}_{2}$ (até 2,60\%) e $\mathrm{FeO}$, enquanto $\mathrm{Bt}_{1}$ mostra maiores $\mathrm{X}_{\mathrm{Mg}}$ (Tab. 2), sugerindo que o titânio foi mobilizado, preferencialmente em conjunto com o ferro, em relação ao magnésio.

Ainda nos leucogranitos, granada com espessartita acima de $10 \%$ sugere cristalização a partir de líquido magmático tardio (Miller \& Stoddard 1978 apud Allan \& Clarke 1981). Granada próxima de biotita cloritizada (Fig. 7a) em condições subsolidus sugere a seguinte reação:

$$
\begin{aligned}
& 3 \mathrm{~K}_{2}\left(\mathrm{Mg}_{\mathrm{x}}, \mathrm{Fe}_{\mathrm{y}}\right)_{4}\left(\mathrm{Fe}_{\mathrm{a}}{ }_{\mathrm{a}}, \mathrm{Al}_{\mathrm{b}}, \mathrm{Ti}_{\mathrm{c}}\right)_{2}\left[\mathrm{Si}_{6} \mathrm{Al}_{2} \mathrm{O}_{20}\right](\mathrm{OH}, \mathrm{F})_{4}+16 \mathrm{H}_{(\text {(iq) }}^{+}+ \\
& \mathrm{Bt} \\
& 6\left(\mathrm{Mn}_{\mathrm{d}}\right)_{(\mathrm{iiq})} \Rightarrow 2\left(\mathrm{Mn}_{\mathrm{d}}, \mathrm{Fe}^{+3}{ }_{\mathrm{a}}\right)_{3} \mathrm{Al}_{\mathrm{b}} \mathrm{Si}_{3} \mathrm{O}_{12}+\left(\mathrm{Mg}_{\mathrm{x}}, \mathrm{Al}_{\mathrm{b} 6}, \mathrm{Fe}_{\mathrm{y}}\right)_{12} \\
& \text { Grt } \mathrm{Chl} \\
& \left(\mathrm{Si}_{6} \mathrm{Al}_{2} \mathrm{O}_{20}\right)(\mathrm{OH})_{16}+4\left[\mathrm{Al}(\mathrm{OH})_{3}\right]_{(\mathrm{fl})}+6\left(\mathrm{~K}^{+}, \mathrm{Si}^{+4}, \mathrm{Ti}_{\mathrm{c}}\right)_{(\mathrm{iq})}
\end{aligned}
$$

Por sua vez, nos paragnaisses não-granadíferos do CS, fibrolita substituindo cordierita (Fig. 5d) 
Tabela 6 - Análises químicas representativas de muscovita.

\begin{tabular}{|c|c|c|c|c|c|c|c|c|c|c|c|}
\hline Amostras & 012 & 012 & 012 & 073 & 073 & 073 & 082 & 082 & $29 \mathrm{E} 4$ & $29 \mathrm{E} 5$ & 056 \\
\hline Posição & $10 \mathrm{c}+$ & $16 \mathrm{c}^{*}$ & $17 b^{*}$ & $13 c+$ & $14 \mathrm{~b}+$ & $45 c^{*}$ & $09 c^{*}$ & $31 \mathrm{c}+$ & $18 \mathrm{c} \boldsymbol{\Delta}$ & $38 \mathrm{c} \mathrm{O}$ & A33 $\nabla$ \\
\hline $\mathrm{SiO}_{2}$ & 45,10 & 45,26 & 44,70 & 46,34 & 46,56 & 45,88 & 45,41 & 45,83 & 45,89 & 44,72 & 45,02 \\
\hline $\mathrm{TiO}_{2}$ & 0,48 & 0,15 & 0,31 & 0,87 & 0,88 & 0,15 & 0,21 & 0,83 & 0,892 & 0,270 & 0,410 \\
\hline $\mathrm{Al}_{2} \mathrm{O}_{3}$ & 33,31 & 32,68 & 32,53 & 35,95 & 36,28 & 36,56 & 35,86 & 35,48 & 34,94 & 34,72 & 36,79 \\
\hline $\mathrm{Cr}_{2} \mathrm{O}_{3}$ & 0,00 & 0,00 & 0,03 & 0,11 & 0,18 & 0,08 & 0,05 & 0,10 & 0,015 & 0,000 & 0,000 \\
\hline $\mathrm{FeO}$ & 4,17 & 4,19 & 4,20 & 0,67 & 0,47 & 0,64 & 0,71 & 0,77 & 1,711 & 2,033 & 0,920 \\
\hline $\mathrm{MnO}$ & 0,08 & 0,02 & 0,05 & 0,02 & 0,00 & 0,03 & 0,00 & 0,00 & 0,004 & 0,040 & 0,000 \\
\hline $\mathrm{MgO}$ & 0,59 & 1,07 & 1,06 & 0,53 & 0,44 & 0,42 & 0,43 & 0,45 & 0,695 & 0,600 & 0,350 \\
\hline $\mathrm{CaO}$ & 0,02 & 0,00 & 0,00 & 0,04 & 0,00 & 0,02 & 0,03 & 0,03 & 0,000 & 0,000 & 0,010 \\
\hline $\mathrm{Na}_{2} \mathrm{O}$ & 0,33 & 0,54 & 0,57 & 1,29 & 1,46 & 1,45 & 1,32 & 1,30 & 0,288 & 0,280 & 0,360 \\
\hline $\mathrm{K}_{2} \mathrm{O}$ & 10,75 & 10,58 & 10,67 & 8,74 & 9,19 & 9,17 & 9,79 & 9,51 & 10,59 & 11,08 & 10,43 \\
\hline $\mathrm{H}_{2} \mathrm{O}$ & 4,44 & 4,43 & 4,40 & 4,54 & 4,56 & 4,51 & 4,45 & 4,48 & 4,000 & 4,420 & 4,490 \\
\hline Total & 99,25 & 98,92 & 98,53 & 99,13 & 100,1 & 98,93 & 98,25 & 98,77 & 100,0 & 99,16 & 98,78 \\
\hline $\mathrm{Si}$ & 3,047 & 3,063 & 3,045 & 3,063 & 3,063 & 3,049 & 3,058 & 3,067 & 3,100 & 3,033 & 3,004 \\
\hline $\mathrm{Ti}$ & 0,024 & 0,008 & 0,016 & 0,043 & 0,044 & 0,008 & 0,011 & 0,042 & 0,045 & 0,014 & 0,021 \\
\hline $\mathrm{Al}$ & 2,652 & 2,607 & 2,612 & 2,800 & 2,813 & 2,863 & 2,846 & 2,799 & 2,722 & 2,775 & 2,894 \\
\hline $\mathrm{Cr}$ & 0,000 & 0,000 & 0,002 & 0,006 & 0,009 & 0,004 & 0,003 & 0,005 & 0,001 & 0,000 & 0,000 \\
\hline $\mathrm{Fe} 2$ & 0,212 & 0,213 & 0,215 & 0,033 & 0,006 & 0,032 & 0,040 & 0,043 & 0,095 & 0,115 & 0,046 \\
\hline $\mathrm{Mn}$ & 0,005 & 0,001 & 0,003 & 0,001 & 0,000 & 0,002 & 0,000 & 0,000 & 0,000 & 0,002 & 0,000 \\
\hline $\mathrm{Mg}$ & 0,060 & 0,108 & 0,107 & 0,052 & 0,043 & 0,042 & 0,043 & 0,045 & 0,069 & 0,060 & 0,035 \\
\hline $\mathrm{Ca}$ & 0,001 & 0,000 & 0,000 & 0,003 & 0,000 & 0,002 & 0,002 & 0,002 & 0,000 & 0,000 & 0,000 \\
\hline $\mathrm{Na}$ & 0,043 & 0,071 & 0,076 & 0,166 & 0,187 & 0,187 & 0,172 & 0,168 & 0,037 & 0,037 & 0,047 \\
\hline $\mathrm{K}$ & 0,926 & 0,913 & 0,927 & 0,737 & 0,771 & 0,778 & 0,841 & 0,812 & 0,890 & 0,958 & 0,888 \\
\hline $\mathrm{H}$ & 2,000 & 2,000 & 2,000 & 2,000 & 2,000 & 2,000 & 2,000 & 2,000 & 2,000 & 2,000 & 2,000 \\
\hline $\mathrm{XMg}(\mathrm{FeT})$ & 0,219 & 0,336 & 0,332 & 0,609 & 0,632 & 0,565 & 0,517 & 0,508 & 0,420 & 0,343 & 0,431 \\
\hline $\mathrm{Al}\left(\left(^{\mathrm{IV}}\right)\right.$ & 0,953 & 0,937 & 0,955 & 0,937 & 0,937 & 0,951 & 0,942 & 0,933 & 0,900 & 0,967 & 0,996 \\
\hline $\mathrm{Al}\left({ }^{\mathrm{VI}}\right)$ & 1,700 & 1,670 & 1,657 & 1,863 & 1,876 & 1,912 & 1,904 & 1,866 & 1,822 & 1,808 & 1,898 \\
\hline Oxigênios & 11 & 11 & 11 & 11 & 11 & 11 & 11 & 11 & 11 & 11 & 11 \\
\hline ¿cátions & 6,970 & 6,985 & 7,003 & 6,905 & 6,958 & 6,967 & 7,015 & 6,983 & 6,960 & 6,996 & 6,935 \\
\hline
\end{tabular}

c-centro; b-bordo.

012 - paragnaisse não-granadífero do CS; 073 e 082 - xisto aluminoso da BJ; 29E4 e 29E5 - filão granadífero associado ao leucogranito

Saracura; 56 - fácies granadífera no leucogranito Cachoeira Grande.

* - muscovita de substituição de feldspato; +- muscovita de substituição ou associada à biotita; $\boldsymbol{\Delta}$ - muscovita ígnea (?);O - muscovita

associada à biotita; $\nabla$ - muscovita de substituição de fibrolita.

ou plagioclásio (Fig. 5e) sugere as seguintes reações (Kerrick, 1988):

$$
\begin{aligned}
& (\mathrm{Mg}, \mathrm{Fe})_{2} \mathrm{Al}_{4} \mathrm{Si}_{5} \mathrm{O}_{18}+4 \mathrm{H}^{+} \Rightarrow 2 \mathrm{Al}_{2} \mathrm{SiO}_{5}+2(\mathrm{Mg}, \mathrm{Fe})^{+2}+ \\
& \text { Crd Sill (Fib) } \\
& +2 \mathrm{H}_{2} \mathrm{O}+3 \mathrm{SiO}_{2} \\
& \mathrm{e} \\
& 5 \mathrm{Na}_{0,8} \mathrm{Ca}_{0,2} \mathrm{Al}_{1,2} \mathrm{Si}_{2,8} \mathrm{O}_{8}+6 \mathrm{H}+\Rightarrow 3 \mathrm{Al}_{2} \mathrm{SiO}_{5}+4 \mathrm{Na}^{+}+\mathrm{Ca}^{+2}+ \\
& \mathrm{Pl} \quad \text { Sill (Fib) } \\
& +3 \mathrm{H}_{2} \mathrm{O}+11 \mathrm{SiO}_{2}
\end{aligned}
$$

A muscovita cresceu tardiamente nos leucogranitos (Figs. 7b,c) e nas rochas metassedimentares (Fig. 5e). A que substitui a fibrolita contém até $4,2 \%$ de $\mathrm{FeO}$ e $1,07 \%$ de $\mathrm{MgO}$, sugerindo a reação abaixo:

$$
\begin{aligned}
& 2 \mathrm{Al}_{2} \mathrm{SiO}_{5}+4\left[\mathrm{KAl}_{\mathrm{a}}(\mathrm{OH})_{4}\right]_{(\mathrm{fl})}+10\left(\mathrm{SiO}_{2}\right)_{(\mathrm{fl})}+8\left(\mathrm{Mg}^{+2}{ }_{\mathrm{b}},\right. \\
& \mathrm{Sill}(\mathrm{Fib}) \\
& \left.8 \mathrm{Fe}^{+2}, 8 \mathrm{Fe}^{+3}\right)_{\mathrm{d}_{(\mathrm{fl})}}+2 \mathrm{H}_{2} \mathrm{O} \Rightarrow 2 \mathrm{~K}_{2}\left(\mathrm{Al}_{\mathrm{a} / 2}, \mathrm{Mg}^{+2}{ }_{\mathrm{b}}, \mathrm{Fe}^{+2}{ }^{+} \mathrm{Fe}^{+3}{ }_{\mathrm{d}}\right)_{4} \\
& \left(\mathrm{Si}_{6} \mathrm{Al}_{2} \mathrm{O}_{20}\right)(\mathrm{OH})_{4}+12 \mathrm{H}^{+} \\
& \quad \mathrm{Ms}
\end{aligned}
$$

A reação (13) mostra que mesmo nos estágios tardios da evolução metassomática, os fluidos redutores foram realimentados por íons de hidrogênio.

A figura 10 contém uma síntese das reações me- 


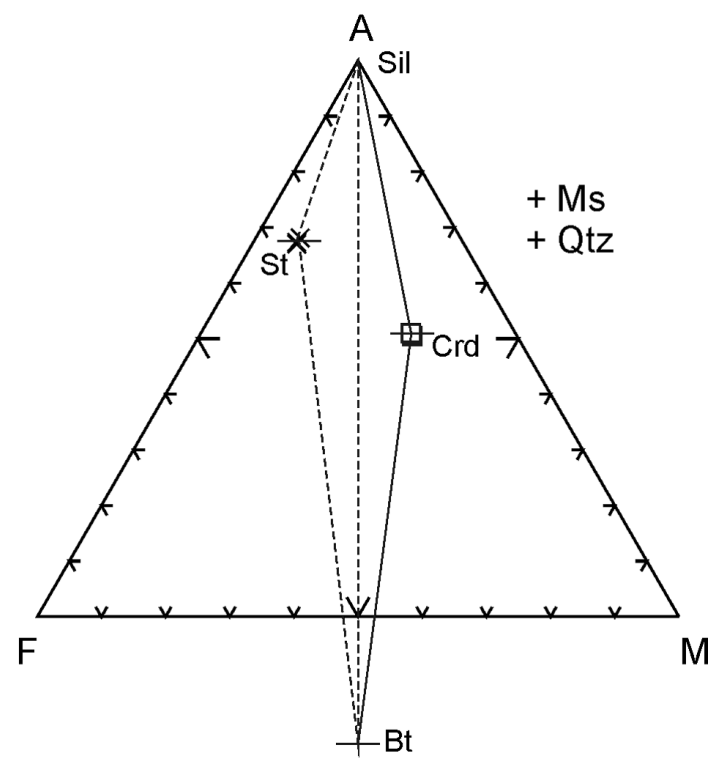

Figura 9 - Diagrama AFM (Thompson 1957) mostrando a incompatibilidade de equilíbrio entre estaurolita e cordierita nos paragnaisses não-granadíferos do CS. tassomáticas descritas.

Estimativas de $\boldsymbol{P}$ - $\boldsymbol{T}$ Para estimativas das condições de pressão e temperatura em que foram cristalizadas as assembléias mineralógicas em foco, utilizou-se o software TWEEQU (Berman 1991), versão winTWQ (2007), e geotermobarômetros de calibração direta (Dasgupta et al. 1991, Bhattacharya et al. 1988, Hoisch 1989, Perchuk 1991).

Nos kinzigitos do CS, a assembléia mineralógica $\mathrm{Grt}+\mathrm{Sil}+\mathrm{Qtz}+\mathrm{Crd}+\mathrm{Pl}+\mathrm{Bt}$ constitui um geotermobarômetro (Harris \& Holland 1984) cujas estimativas calculadas com a versão winTWQ (2007) estão entre 700 e $750^{\circ} \mathrm{C}$ e 3,5 e $4,5 \mathrm{kbar}$. Os dados térmicos podem refletir temperaturas de fechamento para a intertroca Fe-Mg entre granada, cordierita e biotita, todavia, as análises químicas dos núcleos dos porfiroblastos destes minerais, aplicadas nos métodos de calibração direta, mostram que as temperaturas obtidas estão entre a transição fácies anfibolito alto/ granulito (Tab. 7).

Com relação aos paragnaisses não-granadíferos do CS, a ausência da granada não permite a obtenção de dados barométricos. Entretanto, estimativas de pressões

Tabela 7 - Dados de geotermobarometria para os kinzigitos do CS.

\begin{tabular}{|c|c|c|c|c|c|}
\hline & Amostras & 138 & 17 & 23 & 24 \\
\hline \multicolumn{2}{|c|}{ Pressão ultilizada para os cálculos } & $3,5-5,0 \mathrm{kbar}$ & $3,5-5,0 \mathrm{kbar}$ & $3,5-5,0 \mathrm{kbar}$ & $\begin{array}{c}3,5-5,0 \\
0 \mathrm{kbar}\end{array}$ \\
\hline \multicolumn{6}{|c|}{ GEOTERMÔMETROS $\left({ }^{\circ} \mathrm{C}\right)$} \\
\hline $\mathrm{Grt}+\mathrm{Bt}$ & Dasgupta et al. (1991) & $640-750$ & $610-750$ & $750-830$ & $710-830$ \\
\hline $\mathrm{Grt}+\mathrm{Crd}$ & Bhattacharya et al. (1988) & $650-710$ & $680-750$ & $620-720$ & $650-730$ \\
\hline
\end{tabular}

Tabela 8 - Geotermometria dos paragnaisses não-granadiferos do CS existos aluminosos da BJ.

\begin{tabular}{c|c|c|c|c|c|c}
\hline \multicolumn{2}{c|}{ Amostras } & $12 *$ & $74 *$ & $20504+$ & $73++$ & $82++$ \\
\hline \multicolumn{5}{c|}{ GEOTERMÔMETROS $\left({ }^{\circ} \mathrm{C}\right)$} \\
\hline Pressão ultilizada para os cálculos & $2,0-3,0 \mathrm{kbar}$ & $3,0-5,0 \mathrm{kbar}$ & $3,0-5,0 \mathrm{kbar}$ & $3,0-5,0 \mathrm{kbar}$ & $3,0-5,0 \mathrm{kbar}$ \\
\hline $\mathrm{Bt}+\mathrm{Mus}$ & Hoisch (1989) & $510-560$ & & & $450-510$ & $480-540$ \\
\hline $\mathrm{Crd}+\mathrm{Pl}+\mathrm{Bt}+\mathrm{Qtz}$ & winTWQ (2007) & & $520-650$ & & & \\
\hline \multirow{2}{*}{$\mathrm{Grt}+\mathrm{St}$} & Perchuk (1991) & & & $560-580$ & & \\
\hline $\mathrm{Grt}+\mathrm{Chl}$ & Perchuk (1991) & & & $570-600$ & & \\
\hline
\end{tabular}

* - paragnaisse não-granadífero do CS; + - estaurolita-granada-clorita-xisto da BJ; ++ - sillimanita-andaluzita-xisto da BJ. 

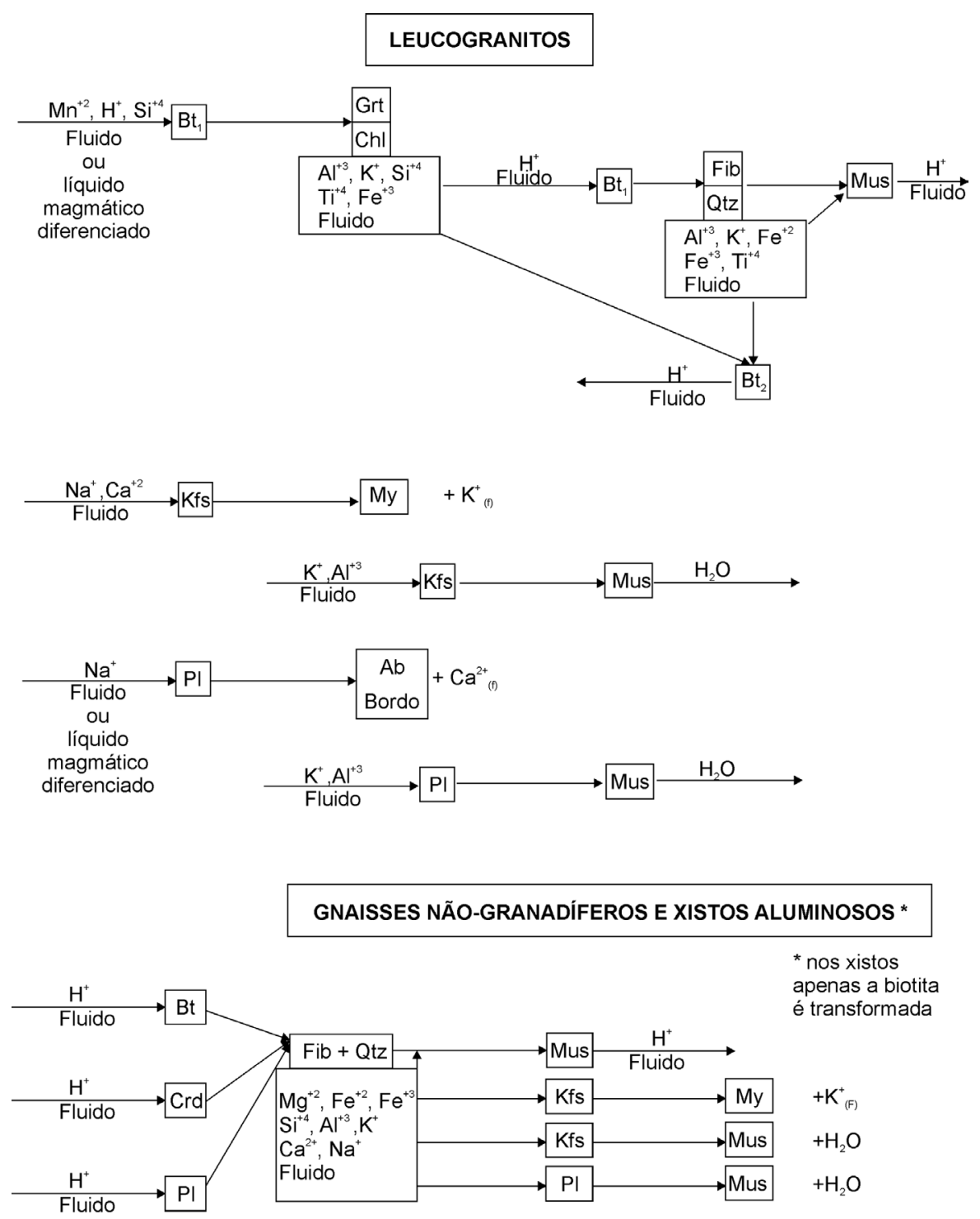

Figura 10 - Esquema para as reações metassomáticas na área de estudo (Leite 2002, Leite et al. 2005). Nos leucogranitos, os minerais foram transformados ou por reações de ressorção com o líquido magmático, cristalizando albita ou por reações metassomáticas no estado subsolidus, cristalizando granada, fibrolita, mirmequita e muscovita. Nas rochas metassedimentares ocorrem esses três últimos minerais, sugerindo evento comum de circulação de fluidos.

mínimas de 3,0 kbar podem ser propostas, em função da presença da estaurolita (Spear 1993). Assim, estimamse temperaturas entre 520 e $650^{\circ} \mathrm{C}$ para a assembléia $\mathrm{Crd}+\mathrm{Pl}+\mathrm{Bt}+\mathrm{Qtz}$, utilizando-se o método winTWQ (2007) e, entre 510 e $560^{\circ} \mathrm{C}$ para o geotermômetro $\mathrm{Bt}+$ Ms (Hoisch 1989) (Tab. 8).

O estaurolita-granada-clorita-xisto da BJ, assim como as rochas portadoras de andaluzita não permitem estimativas de pressão: a primeira devido à ausência de um polimorfo de $\mathrm{Al}_{2} \mathrm{SiO}_{5}$ enquanto as últimas por não conterem granada. Entretanto, pressões mínimas de 3,0 kbar podem ser estimadas para o metamorfismo dessas rochas devido à presença do par Grt $+\mathrm{St}$ sem biotita (Spear 1993) e pela presença de cianita em algumas rochas da BJ (Leo et al. 1964). Além disso, a reação (05) é demarcada por uma reta univariante de forte declividade no diagrama P-T e constitui um geotermômetro com $\mathrm{T} \approx 525^{\circ} \mathrm{C}$ (Spear \& Cheney 1989) e os geotermômetros Grt + Chl e Grt + St (Perchuk 1991) fornecem dados entre 560 e $600^{\circ} \mathrm{C}$. Para os xistos com andaluzita da BJ, as estimativas com o par Bt + Ms (Hoisch 1989) estão entre 450 e $540^{\circ} \mathrm{C}$ (Tab. 8).

$\mathrm{O}$ cálculo das condições de $P-T$ em que são formados e/ ou intrudidos os magmas graníticos deixa dúvidas sobre os resultados obtidos, haja vista que os modelos envolvendo as atividades dos componentes e os membros-finais das soluções sólidas dos minerais que são utilizados nos calibradores diretos não se aplicam para os sistemas graníticos (Anderson 1996). Entretanto, Leite (2002) utilizou o geotermômetro basea- 
do no modelo da solubilidade do zircônio em magmas peraluminosos (Watson \& Harrison 1983) e calculou temperaturas entre 738 e $829^{\circ} \mathrm{C}$.

Trajetória $P-T$ do metamorfismo/ metassomatismo O significado petrogenético das microestruturas ao lado das estimativas termobarométricas de formação das assembléias mineralógicas permitem traçar as trajetórias $P$ - $T$ pelas quais passaram as rochas investigadas. Estas trajetórias se dão no intervalo de tempo compreendido entre a colisão continental e o subseqüente relaxamento termal dos segmentos crustais envolvidos (England \& Thompson 1984).

Os paragnaisses não-granadíferos do CS e os xistos aluminosos da BJ apresentam uma seqüência de reações metamórficas que são reconhecidas na grade petrogenética de Spear \& Chenney (1989). A reação (05) de formação da estaurolita e as reações de sua desestabilização (03 e 07), além da reação de cristalização da cordierita (04) são representadas nessa grade petrogenética por curvas univariantes de forte declividade, segundo intervalos de temperaturas entre 500 e $650^{\circ} \mathrm{C}$ (Fig. 11). As inclusões de sillimanita em cordierita e em andaluzita mostram que a primeira cristalizou antes da fibrolita a qual se formou por substituição da cordierita e após o crescimento da andaluzita. Essas feições indicam aumento do grau geotérmico, durante ou pós-descompressão orogênica. $\mathrm{O}$ aumento do grau geotérmico

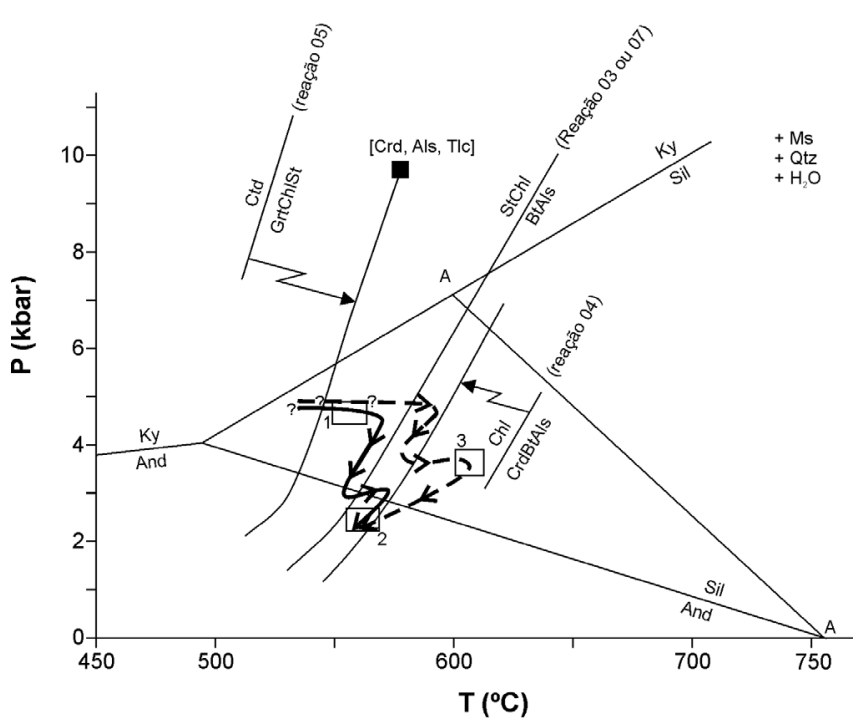

Figura 11 - Trajetórias $P-T$ da evolução metamórfica dos paragnaisses não-granadíferos (trajetória tracejada) e dos xistos aluminosos (trajetória cheia) no sistema KFMASH. A grade petrogenética parcial e os campos de estabilidade dos polimorfos de $\mathrm{Al}_{2} \mathrm{SiO}_{5}$ são de Spear \& Cheney (1989). Os retângulos 1, 2 e 3 referem-se aos dados de geotermometria obtidos com os métodos Grt + St (Perchuck 1991), Bt + Ms (Hoisch 1989) e win-TWQ (versão 2007, Berman 1991) para a assembléia $C r d+B t+P l+Q t z$, respectivamente. $A$ reta $A-A$ delimita o campo da metaestabilidade da andaluzita no campo da fibrolita (Salje 1986). provocou inflexão das trajetórias $P-T$ para mais altas temperaturas (Fig. 11). Como a cristalização da fibrolita está associada à circulação dos fluidos redutores, essa inflexão corresponde à mudança das condições de metamorfismo para as de metassomatismo.

A relação da andaluzita com a fibrolita possui também significado geodinâmico. Os dados experimentais de Salje (1986), envolvendo sillimanita prismática e fibrolita, mostram que a última torna-se estável a temperaturas mais altas devido à sua maior capacidade de calor e da sua maior entropia de vibração. Em conseqüência, a reta de equilíbrio Andaluzita = Fibrolita estaria em posição mais alta no diagrama $P-T$, aumentando o campo de estabilidade da andaluzita. Kerrick (1990) sugeriu que este posicionamento seria conseqüência do equilíbrio metaestável da andaluzita no campo de estabilidade da fibrolita.

IMPLICAÇÕES TECTÔNICAS A ausência de fibrolita e muscovita nos kinzigitos e as estimativas de temperaturas de cristalização na fácies granulito (750 a $830^{\circ} \mathrm{C}$, Tab.7) sugerem um posicionamento alóctone dessas rochas que seriam provenientes das porções mais profundas do orógeno. Essa hipótese tem apoio nos dados estruturais, tais como, as lineações de estiramento mineral e as mini-dobras assimétricas que indicam transporte tectônico de leste para oeste, isto é, do Cinturão Itabuna-Salvador-Curaçá para o Bloco Gavião (Fig. 4) (Loureiro 1991, Leite 2002). Em adição, fibrolita só está presente nos leucogranitos, nos paragnaisses não-granadíferos e nos metapelitos da Bacia Jacobina, sugerindo que o front de metassomatismo ocorreu entre essas rochas. Isto implica também compreender o significado geodinâmico dos paragnaisses não-granadíferos. Estes paragnaisses estão metamorfizados em condições crustais mais rasas em relação aos kinzigitos, haja vista a ausência da granada e a presença da muscovita, em comum com os xistos aluminosos. Assim, no contexto evolutivo da orogenia riaciana/ orosiniana na área, esses paragnaisses podem representar unidade metassedimentar da Bacia Jacobina, conforme proposto por Ledru et al. (1997). Outra possibilidade é interpretar que essa unidade metassedimentar seja alóctone, tal como os kinzigitos, mas que estaria posicionada no mesmo nível crustal, em relação ao da Bacia Jacobina.

As cristalizações da fibrolita e da muscovita indicam que o metassomatismo se deu tardiamente na descompressão orogênica, em condições de aumento da temperatura (cristalização da fibrolita) seguido por nova queda da temperatura (cristalização da muscovita). Estes minerais fazem parte da assembléia mineralógica subsolidus dos leucogranitos, sugerindo que a intrusão do magmatismo peraluminoso representou fonte adicional de calor para as rochas metassedimentares e funcionou como catalisador termodinâmico de remobilização dos fluidos crustais.

CONCLUSÕES Os metapelitos do Complexo Saúde e da Bacia Jacobina contêm relictos (granada, sillimanita e estaurolita) de paragêneses metamórficas forma- 
das durante a trajetória progressiva de metamorfismo regional de média pressão (3,5-5,0 kbar). Por outro lado, suas assembléias minerais com cordierita ou andaluzita demarcam trajetórias retrógradas, associadas à exumação/ soerguimento orogênico. Todavia, fibrolita e muscovita, presentes nos paragnaisses não-granadíferos, xistos e leucogranitos, indicam evento regional de metassomatismo durante a trajetória $P-T$ tardi a pós-soerguimento orogênico. Em contraste, a mineralogia dos kinzigitos não contém fibrolita e muscovita e mostram estimativas geotermométricas da fácies granulito, sugerindo que essas rochas representem unidade alóctone sobre o Bloco Gavião.

O evento de metassomatismo é caracterizado pela lixiviação preferencial de ferro, titânio e alumínio, em relação ao magnésio, por percolação dos fluidos redutores atuando sobre os minerais metamórficos das rochas metassedimentares ou em condições subsolidus nos leucogranitos.

A intrusão dos leucogranitos além de aumen- tar o grau geotérmico durante o soerguimento orogênico, provocou remobilização de fluidos crustais. Esta combinação de fatores foi responsável por mudanças nas trajetórias regressivas $P-T$ dos paragnaisses nãogranadíferos e dos xistos aluminosos em direção a temperaturas próximas de $600^{\circ} \mathrm{C}$.

Agradecimentos Os autores agradecem ao Dr. Phillipe Goncalves, então doutorando da Université Blaise Pascal, pelo apoio e discussões sobre as problemáticas investigadas, durante o período do Doutorado-Sanduíche de Carlson Leite nesta universidade. Somos agradecidos também à Madame Michelle Veschambre pelo acesso a microssonda eletrônica, à Companhia Baiana de Pesquisa Mineral pelo apoio logístico durante as viagens de campo e aos revisores da RBG pelas sugestões ao manuscrito. Carlson Leite agradece à Coordenação de Aperfeiçoamento do Pessoal de Nível Superior (CAPES) pela concessão das bolsas de estudos na UFBA e de Doutorado-Sanduíche na França.

\section{Referências}

Allan B. D. \& Clarke D. B. 1981. Occurrence and origin of garnets in the South Mountain batholith. Can. Mineral. 19:19-24.

Almeida F.F.M. de. 1967. Origem e evolução da plataforma brasileira. Rio de Janeiro, DNPM/DGM, Boletim 241, $36 \mathrm{p}$.

Anderson J. L. 1996. Status of thermobarometry in granitic batholiths. Trans. Royal Soc. Edinb. Earth Sci. 87:125138.

Barbosa J. F. S. \& Sabaté P. 2002. Geological features and the Paleoproterozoic collision of four Archean crustal segments of the São Francisco Craton, Bahia, Brazil. A synthesis. Anais da Academia Brasileira de Ciências, 74:343-359.

Barbosa J. S. F.\& Sabaté P. 2004. Archean and Paleoproterozoic crust of the São Francisco Craton, Bahia, Brazil: geodynamic features. Precamb. Res. 133:1-27.

Bhattacharya A, Mazumdar A. C., Sen S. K. 1988. Fe-Mg mixing in cordierite: constraints from natural data and implications for cordierite-garnet geothermometry to granulites. Am. Mineral, 73:338-344.

Berman R. G. 1991. Thermobarometry using multi-equilibrium calculations: a new technique with petrological applications Can. Mineral. 29:833-855.

Bjerg S., Mogessie A., Bjerg E. 1995. A mineral formula calculation program (PAS-FORM).

Couto P. A., Delgado I. M., Mascarenhas J. F., Batista M. B., Pedreira A. J., Siqueira L.P., Bruni D.C., Gonçalves G. D., Sampaio A R., Gil C. A., Loureiro H. S., Awdziej J., Arcanjo J.B., Fernandes Filho J., Guimarães J. T., Silva L. C., Melo R.C., Toledo L. A. A., Machado G. J., Maron J.E., Oliveira J. E., Rodrigues V., Frana F. B., Teixeira A. J., Silva H. P., Margalho R., Brito P. C., Kipper D., Cãs M. G., Bani R., Campelo R. 1978. Projeto Serra de Jacobina-Geologia e Prospecção Geoquímica. Salvador, DNPM/CPRM, Relatório Final, CPRM, 12v.

Cuney M., Sabaté P., Vidal P., Marinho M. M., Conceição H.
1990. The 2 Ga peraluminous magmatism of JacobinaContendas-Mirante Belt (Bahia) Brazil: Major and trace element geochemistry and metallogenetic potential. $J$. Volcan. and Geother. Res., 44:123-141.

Dasgupta S., Sengupta P., Guha D., Fukuoka M. 1991. A refined garnet-biotite, Fe-Mg exchange geothermometer and its application in amphibolites and granulites. Contrib. Mineral. Petrol. 109:130-137.

England P. C., Thompson A. B. 1984. Pressure-TemperatureTime paths of regional metamorphism I. Heat transfer during the evolution of regions of thickened continental crust. J. Petrol., 25:894-928.

Foster C. T. 1977. Mass transfer in sillimanite-bearing pelitic schists near Rangeley, Maine. Am. Mineral. 62:727746.

Guidotti C. V., Cheney J. T., Guggenheim S. 1977. Distribution of titanium between coexisting muscovite and biotite in pelitic schists from northwestern Maine. Am. Mineral. 62:438-448.

Harris N.B.W., Holland, T.J.B. 1984. The significance of cordierite-hypersthene assemblages from the Beitbridge Region of the Central Limpopo Belt: evidence for rapid decompression in the Archean? Am. Mineral. 69: 10361049.

Hoisch T.D. 1989. A muscovite-biotite geothermometer. Am. Mineral. 74: 565-572.

Holdaway M.J., Dutrow B.L., Shore P. 1986. A model for the crystal chemistry of staurolite. Am. Mineral. 71: 1142-1159.

Kerrick D.M. 1988. $\mathrm{Al}_{2} \mathrm{SiO}_{5}$-bearing segregations in the Lepontine Alps, Switzerland: aluminium mobility in metapelites. Geology. 16: 636-640.

Kerrick D.M. 1990. The $\mathrm{Al}_{2} \mathrm{SiO}_{5}$ Polymorphs. Washington D. C., Reviews in Mineralogy, vol. 22, Mineralogical Society of America, $406 \mathrm{p}$.

Kretz R. 1983. Symbols for rock-forming minerals. Am. Mineral. 68: 277-279. 
Ledru P., Milési J. P., Johan V., Sabaté P., Maluski H. 1997. Foreland basins and gold- bearing conglomerates: a new model for the Jacobina Basin (São Francisco Province, Brazil). Precamb. Res. 86:155-176.

Leo G.W., Cox D.P., Carvalho J.P.P. 1964. Geologia da parte sul da Serra de Jacobina, Bahia, Brasil. Rio de Janeiro. DNPM/DGM, Boletim 241, 123p.

Leite C.M.M. 2002. A Evolução Geodinâmica da Orogênese Paleoproterozóica nas regiões de Capim Grosso-Jacobina e Pintadas-Mundo Novo (Bahia-Brasil): Metamorfismo, Anatexia e Tectônica. Tese de Doutoramento, Universidade Federal da Bahia, Salvador, 412p.

Leite C.M.M., Barbosa J. S. F., Nicollet C. 2005. Nódulos de quartzo + sillimanita em cinturões orogênicos: petrogênese e significado geodinâmico na evolução do Orógeno Itabuna-Salvador-Curaçá na região de Mundo Novo, Bahia. In: SBG, Simp. Cráton do São Francisco, 3, Anais, p.235-238.

Leite C.M.M., Barbosa J.S.F., Nicollet C., Sabaté P. 2001. A evolução do magmatismo peraluminoso em zonas de cisalhamento de transpressão paleoproterozóicas no Orógeno Salvador-Curaçá , nordeste do Estado da Bahia, Brasil. In: SBG, Simp. Nac. de Est. Tect., 8, Recife, Anais, 257-262.

Loureiro H.S.C. 1991. Programa Levantamentos Geológicos Básicos do Brasil. Mundo Novo. Folha SC-24-Y-D-IV. Escala 1:100.000., DNPM/ CPRM/ SUREG-SA, 196 p.

Marinho M. M. \& Sabaté P. 1982. The Contendas-Mirante volcano-sedimentary sequence and its granitic migmatitic basement. In: SME/ CPM, Internat. Symp. Archean and Early Proterozoic Geologic Evolution and Metallogenesis (ISAP), Excursion guide, p.139-184.

Mascarenhas J.F. \& Silva E.F.A. 1994. Greenstone Belt de Mundo Novo: caracterização e implicações metalogenéticas e geotectônicas no Cráton do São Francisco. Salvador, CBPM, Série Arquivos Abertos, 5, 32 p.

Mascarenhas J. F., Ledru P., Souza S. L., Conceição Filho V. M., Melo L. F. A., Lorenzo C. L., Milési J. P. 1998. Geologia e recursos minerais do Grupo Jacobina e da parte sul do Greenstone Belt de Mundo Novo. Salvador, CBPM, Série Arquivos Abertos, 13, 58 p.

Melo R.C., Loureiro H. S. C., Pereira L.H. M. 1995. Programa Levantamentos Geológicos Básicos do Brasil. Serrinha. Folha SC-24-Y-D. Escala 1: 250.000. Brasília, MME/CPRM, 80 p.

Mougeot R. 1996. Étude de la limite Archéen-Protérozoique et des mineralisations $\mathrm{Au}, \pm U$ associées: Exemples des régions de Jacobina (Etat de Bahia, Brésil) et de Carajás (Etat de Pará, Brésil). Montpellier, França, Thèse Doctorat, Université Montepellier II, 30p.

Passchier C.W., Trouw R.A.J. 1996. Microtectonics. Berlim, Springer-Verlag, 289 p.

Pattison D.R.M., Spear F.S., Chenney J.T. 1999. Polymetamorphic origin of muscovite + cordierite + staurolite + biotite assemblages: implications for the metapelitic petrogenetic grid and for P-T paths. J. Metam. Geol., 17:685-703.

Peucat J.J., Mascarenhas J.F., Barbosa J.S.F., Souza S.L., Marinho M.M., Fanning C.M., Leite, C.M.M. 2002. 3.3 $\mathrm{Ga}$ SHRIMP U-Pb zircon age of a felsic metavolcanic rock from the Mundo Novo Greenstone Belt in the São Francisco Craton, Bahia (NE, Brazil). J. of South Amer. of Earth Science, 15:363-373.

Perchuk L. L. 1991. Derivation of a thermodynamically consistent set of geothermometers and geobarometers for metamorphic and magmatic rocks. In: Perchuk L.L. (ed.) Progress in Metamorphic and Magmatic Petrology. A Memorial Volume in Honor of D. S. Korzhinskiy. Cambridge, Cambridge University Press, p.93-112.

Pinho I.C.A. 2005. Geologia dos Metatonalitos/ Metatrondhjemitos e Granulitos Básicos das Regiões de Camamu-Ubaitaba-Itabuna, Bahia. Salvador, Tese de Doutoramento, Universidade Federal da Bahia, 158p.

Sabaté P. 1996. Estruturas e tectônica do embasamento Arqueano/Proterozóico Inferior do Estado da Bahia. In: Barbosa J.S.F. \& Dominguez J.M.L. (eds.) Mapa Geológico do Estado da Bahia, Texto Explicativo. Escala 1: 1.000.000. Salvador, SICM/SGM, 200-226.

Sabaté P., Marinho M. M., Vidal P., Caen-Vachette M. 1990. The 2 Ga peraluminous magmatism of the JacobinaContendas Mirante belts (Bahia, Brazil): Geologic and isotopic constraints on the sources. Chem. Geol., 83:325338.

Salje E. 1986. Heat capacities and entropies of andalusite and sillimanite: The influence of fibrolitization on the phase diagram of the $\mathrm{Al}_{2} \mathrm{SiO}_{5}$ polymorphs. Am. Mineral., 13661371.

Silva L.C., McNaughton N.J., Melo R.C., Fletcher I.R. 1997. U-Pb SHRIMP ages in the Itabuna-Caraíba TTG highgrade Complex: the first window beyond the Paleoproterozoic overprint of the eastern Jequié Craton, NE Brazil. In: SBG/ SICM-Ba, Internat. Symp. on Granites and Associated Mineral., 2, Abstracts, 282-283.

Spear F.S. 1993. Metamorphic Phase Equilibria and Pressure-Temperature-Time Paths. Mineralogical Society of America, Washington D. C., Monograph,799p.

Spear F.S., Cheney J.T. 1989. A petrogenetic grid for pelitic schists in the system $\mathrm{SiO}_{2}-\mathrm{Al}_{2} \mathrm{O}_{3}-\mathrm{FeO}-\mathrm{MgO}-\mathrm{K}_{2} \mathrm{O}-\mathrm{H}_{2} \mathrm{O}$. Contrib. Mineral. Petrol. 101:149-164.

Thompson J. B. Jr. 1957. The graphical analysis of mineral assemblages in pelitic schists. Am. Mineral. 42:842858.

Torquato J.R., Tanner De Oliveira M.A.F., Bartels R.L. 1978. Idade radiométrica do granito de Campo Formoso, Bahia. Uma idade mínima do Grupo Jacobina. Rev. Bras. Geoc., 8:171-179.

Ulmer P. 1993. Calculation of various Mineral-Norms, Program NORM (Version 4.0).

Vernon R. H. 1979. Formation of late sillimanite by hydrogen metasomatism (base-leaching) in some high grade gneisses. Lithos. 12:143-152.

Watson E.B. \& Harrison T.M. 1983. Zircon saturation revisited: temperature and composition effects in a variety of crustal magma types. Earth Planet. Sci. Letters, 64:295304.

Manuscrito AE 094-2006

Submetido em 3 de agosto de 2007 Aceito em 01 dezembro de 2007 